\title{
Transcriptomics analysis of differentially expressed genes in subcutaneous and perirenal adipose tissue of sheep as affected by their pre- and early postnatal malnutrition histories
}

\author{
Sharmila Ahmad ${ }^{1}$, Markus Hodal Drag ${ }^{2}$, Suraya Mohamad Salleh ${ }^{3,4}$, Zexi Cai ${ }^{5}$ and Mette Olaf Nielsen ${ }^{1 *}$
}

\begin{abstract}
Background: Early life malnutrition is known to target adipose tissue with varying impact depending on timing of the insult. This study aimed to identify differentially expressed genes in subcutaneous (SUB) and perirenal (PER) adipose tissue of 2.5-years old sheep to elucidate the biology underlying differential impacts of late gestation versus early postnatal malnutrition on functional development of adipose tissues. Adipose tissues were obtained from 37 adult sheep born as twins to dams fed either NORM (fulfilling energy and protein requirements), LOW (50\% of NORM) or HIGH (110\% of protein and $150 \%$ of energy requirements) diets in the last 6-weeks of gestation. From day 3 to 6 months of age, lambs were fed high-carbohydrate-high-fat (HCHF) or moderate low-fat (CONV) diets, and thereafter the same moderate low-fat diet.

Results: The gene expression profile of SUB in the adult sheep was not affected by the pre- or early postnatal nutrition history. In PER, 993 and 186 differentially expressed genes (DEGs) were identified in LOW versus HIGH and NORM, respectively, but no DEG was found between HIGH and NORM. DEGs identified in the mismatched pre- and postnatal nutrition groups LOW-HCHF (101) and HIGH-HCHF (192) were largely downregulated compared to NORM-CONV. Out of 831 DEGs, 595 and 236 were up- and downregulated in HCHF versus CONV, respectively. The functional enrichment analyses revealed that transmembrane (ion) transport activities, motor activities related to cytoskeletal and spermatozoa function (microtubules and the cytoskeletal motor protein, dynein), and responsiveness to the (micro) environmental extracellular conditions, including endocrine and nervous stimuli were enriched in the DEGs of LOW versus HIGH and NORM. We confirmed that mismatched pre- and postnatal feeding was associated with long-term programming of adipose tissue remodeling and immunity-related pathways. In agreement with phenotypic measurements, early postnatal HCHF feeding targeted pathways involved in kidney cell differentiation, and mismatched LOW-HCHF sheep had specific impairments in cholesterol metabolism pathways.

* Correspondence: mon@anis.au.dk

${ }^{1}$ Nutrition Research Unit, Department of Animal Science, Aarhus University, Blichers Alle 20, 8830 Tjele, Denmark

Full list of author information is available at the end of the article

(c) The Author(s). 2021 Open Access This article is licensed under a Creative Commons Attribution 4.0 International License, which permits use, sharing, adaptation, distribution and reproduction in any medium or format, as long as you give appropriate credit to the original author(s) and the source, provide a link to the Creative Commons licence, and indicate if changes were made. The images or other third party material in this article are included in the article's Creative Commons licence, unless indicated otherwise in a credit line to the material. If material is not included in the article's Creative Commons licence and your intended use is not permitted by statutory regulation or exceeds the permitted use, you will need to obtain permission directly from the copyright holder. To view a copy of this licence, visit http://creativecommons.org/licenses/by/4.0/ The Creative Commons Public Domain Dedication waiver (http://creativecommons.org/publicdomain/zero/1.0/) applies to the data made available in this article, unless otherwise stated in a credit line to the data. 
(Continued from previous page)

Conclusions: Both pre- and postnatal malnutrition differentially programmed (patho-) physiological pathways with implications for adipose functional development associated with metabolic dysfunctions, and PER was a major target.

Keywords: Early life malnutrition, Subcutaneous adipose tissue, Perirenal adipose tissue, Differential expressed genes, Functional enrichment, Long-term programming

\section{Background}

Compromised nutrition during fetal life may alter the growth trajectory of many developing organs, including adipose tissues, due to a phenomenon termed fetal programming. This can lead to tissue malfunction and development of health disorders later in life [1, 2]. In addition to genetic modifications, such nutrient-regulated gene expression may play a major role in the development of adult disease [3].

Fat distribution patterns in the body, capacity of adipose tissues to accommodate nutrient excess, and fat cell size distribution patterns, rather than total fat mass, are major determinant risk factors for predisposition of metabolic disarrangements [4-6]. Subcutaneous adipose tissue (SUB) plays a key role in fat partitioning by preventing nutrient overflow and hence fat deposition elsewhere (e.g. abdominal fats and non-adipose tissue) [7-9], whereas central obesity and ectopic fat deposition are well-known risk factors for insulin resistance and cardiovascular diseases $[10,11]$. In contrast to SUB, the specific roles of perirenal adipose tissue (PER) in relation to development of obesity and associated disorders is less elucidated, and most studies of PER in humans have relied on indirect measurements using ultrasound and other non-invasive approaches [12]. Nevertheless, perirenal fat thickness was shown to be a determining factor for kidney dysfunction and correlated to risk of severe kidney disease and hypertension in humans [13, 14].

We have previously shown in a sheep model that late gestation and early postnatal malnutrition can induce differential, depot and sex-specific changes in adipose developmental traits and metabolic outcomes in adulthood, with PER and SUB as the major targets of prenatal programming in contrast to mesenteric and epicardial adipose tissue [15, 16]. Moreover, in our sheep model we observed a $1 / 3$ reduction in kidney weight of adolescent sheep that had been exposed to an obesogenic high-carbohydrate-high-fat (HCHF) diet in early postnatal life [17]. Furthermore, sheep with a history of prenatal undernutrition followed by early postnatal obesity development developed hypercholesterolemia, which persisted into adulthood even after 2 years of dietary correction [16, 17].

Gene expression profiling studies of adipose tissue have revealed vast numbers of different adipose molecular markers, especially inflammatory genes, that could be linking expanded fat mass and obesity co-morbidities [18]. In this context, nutrition has been shown to program gene expression and development of adipose tissue (i.e. SUB, PER and omental fat) in different animal models [19-22]. Concordantly, using quantitative realtime polymerase chain reaction (qPCR) analysis, we have previously documented impacts of late gestation and early postnatal nutrition interventions on gene expression of well-known markers for adipose development, adipose metabolisms as well as inflammation in four different adipose tissues (SUB, PER, mesenteric and epicardial) of 6-months old lambs and 2.5-years old sheep. However, the early nutrition impacts on gene expression for these markers were poorly associated to observed changes in adipose morphology, cellularity and cell size distributions $[15,23]$.

In this study, we therefore aimed to unravel the genes and/or pathways responsible for the observed changes in adipose morphological traits and the phenotypic manifestations observed in adipose tissue of these animals by using a transcriptomic analysis approach. Application of RNA-sequencing and transcriptomic methodologies could reveal underlying hitherto unknown pathways involved in tissue specific responses to early malnutrition, leading to identification of potential candidate markers for fetal programming (hub genes) and shedding light on the involvement of different adipose tissues in organ and metabolic dysfunctions arising from adverse programming in early life.

\section{Results \\ Mapping summary}

A total of 67 samples $(\mathrm{SUB}=31$ and $\mathrm{PER}=36$, respectively) were analyzed using RNA-sequencing. After filtering, the mean numbers of clean reads per sample obtained from SUB and PER were 34,137,165 and 34, 818,481 , respectively, and were aligned against Ovis aries reference genome (oar_v3.1) using the software package STAR. On average, $83 \%$ of the total reads were successfully mapped allowing no more than eight mismatches and restricting the alignments at most 40 genomic locations. Among the aligned reads, approximately 86 and $65 \%$ were mapped to unique genomic regions in SUB and PER, respectively. The mean coverages of pairedend reads mapping to exonic, intronic, intergenic, and intronic/intergenic regions were 26.48, 36.54, 36.98 and 
$7.28 \%$ for SUB and 19.22, 40.55, 40.22 and $6.01 \%$ for PER, respectively.

\section{Differentially expressed genes (DEGs)}

The lists of differential expressed genes (DEGs) after Benjamini-Hochberg correction, padj $<0.05$ are shown in Table 1, and the direction of change of expression for DEGs for each group comparison are shown in Fig. 1. The gene expression profiles of SUB in the adult sheep were not affected by the pre- or early postnatal nutrition history or sex, except for 44 DEGs identified (padj < 0.05 ) between adult males and females (Additional file 1: Supplementary Table 1).

In PER, 993 DEGs were identified in LOW sheep compared to HIGH, of which 975 and 18 genes were downand upregulated, respectively. Of the known downregulated DEGs, 87 had a fold change (FC) between -4.00 and -5.50 , whereas the FC for the upregulated DEGs was ranging from 0.10 to 0.30 . In LOW vs NORM sheep, 179 upregulated and 7 downregulated DEGs were identified, of which (for the known upregulated DEGs) 25 had an FC $>4.00$. The likelihood ratio test for the interaction between prenatal nutrition and sex revealed 869 out of 873 DEGs were downregulated. There were no DEG identified between HIGH and NORM.

DEG analysis was also done between six combinations of pre- and postnatal nutrition, namely NORM-CONV, NORM-HCHF, LOW-CONV, LOW-HCHF, HIGHCONV, and HIGH-HCHF. Among them, a total of 101 and 192 genes showed significant (padj < 0.05) differential expression between LOW-HCHF vs NORM-CONV and between HIGH-HCHF vs NORM-CONV, respectively. No DEGs were identified for the other group comparisons. In particular, 100 out of 101 and 180 out of 192 genes were downregulated in LOW-HCHF and HIGH-HCHF compared to NORM-CONV, respectively. Of the known downregulated DEGs in LOW-HCHF vs NORM-CONV, 9 had an FC<-3.00, and for HIGHHCHF vs NORM-CONV, 14 had an FC $<-3.00$.

For the independent effect of early postnatal nutrition, 831 DEGs were identified with 595 upregulated and 236 downregulated in HCHF compared to CONV sheep. Of the known upregulated DEGs, 50 had a FC between 4.00 and 5.50, whereas for downregulated DEGs, 13 had a FC between -3.00 to -5.00 . The list of the top 20 known up- and downregulated DEGs for all the group comparison, ranked by $\log 2$ Fold Change $(\log 2 \mathrm{FC})$, are shown in Table 2.

Hub genes, top significant modules, and their respective enrichment identification via protein-protein interaction (PPI) network analyses of DEGs

The Cytoscape StringApp was used to visualize the long lists of DEG network. The DEG networks for all group comparison are shown in Additional file 2: Supplemetary Figure 1A-F. The top 10 DEGs evaluated in the PPI network according to four different centrality criteria (Degree, EcCentrity, EPC, and MNC) are shown in Table 3, and DEGs that topped the lists according to all four criteria were considered to be hub genes. Hence, a total of six hub genes for the LOW vs HIGH comparison, two hub genes for LOW vs NORM, eight hub genes for LOW-HCHF vs NORM-CONV, nine hub genes for HIGH-HCHF vs NORM-CONV, and one hub gene for HCHF vs CONV, were identified as shown in Fig. 2. Among all of the pairwise group comparison, no hub gene was identifed for the PreNxsex. The hubgenes identified for LOW vs HIGH were Aurora Kinase A (AURKA), Exonuclease 1 (EXO1), Maternal Embryonic Leucine Zipper Kinase (MELK) and PDZ Binding Kinase (PDK), NDC80 Kinetochore Complex Component (NDC80 and TTK Protein Kinase (TTK). Those for LOW vs NORM were Coiled-Coil Domain Containing 39 (CCDC39) and Transkelotase Like 1 (TKTL1). The Complement C1q Chain (C1QA), Complement C1q B Chain $(C 1 Q B)$, Colony Stimulating Factor 1 Receptor $(C S F 1 R)$, Cathepsin S (CTSS), Integrin Subunit Beta 2 (ITGB2) and Lysosomal Protein Transmembrane 5 (LAPT M5) were hub genes both for LOW-HCHF and HIGH$\mathrm{HCHF}$ vs NORM-CONV group. Moreover, the Complement C5a Receptor 1 (C5AR1) and Protein Tyrosine Phosphatase Non-Receptor Type 6 (PTPN6) were hub genes for LOW-HCHF vs NORM-CONV, wheares Complement C1q C Chain $(\mathrm{C} 1 \mathrm{QC})$, Spi- Proto-Oncogene (SP11) and Transmembrane Immune Signaling Adaptor TYROBP (TYROBP) were hub genes for HIGH-HCHF vs NORM-CONV. The Matrix Metallopeptidase 9 (MMP9) was the only hub gene for HCHF vs CONV.

Table 1 The number of up- and downregulated DEGs for different group comparison

\begin{tabular}{lllll}
\hline No. & Pairwise contrast & Total DEGs & Upregulated & Downregulated \\
\hline 1 & LOW vs HIGH & 993 & 18 & 975 \\
2 & LOW vs NORM & 186 & 179 & 7 \\
3 & Prenatal nutrition x sex (PreNxsex) & 873 & 171 & 702 \\
4 & LOW-HCHF vs NORM-CONV & 101 & 1 & 100 \\
5 & HIGH-HCHF vs NORM-CONV & 192 & 12 & 180 \\
6 & HCHF vs CONV & 831 & 595 & 236 \\
\hline
\end{tabular}




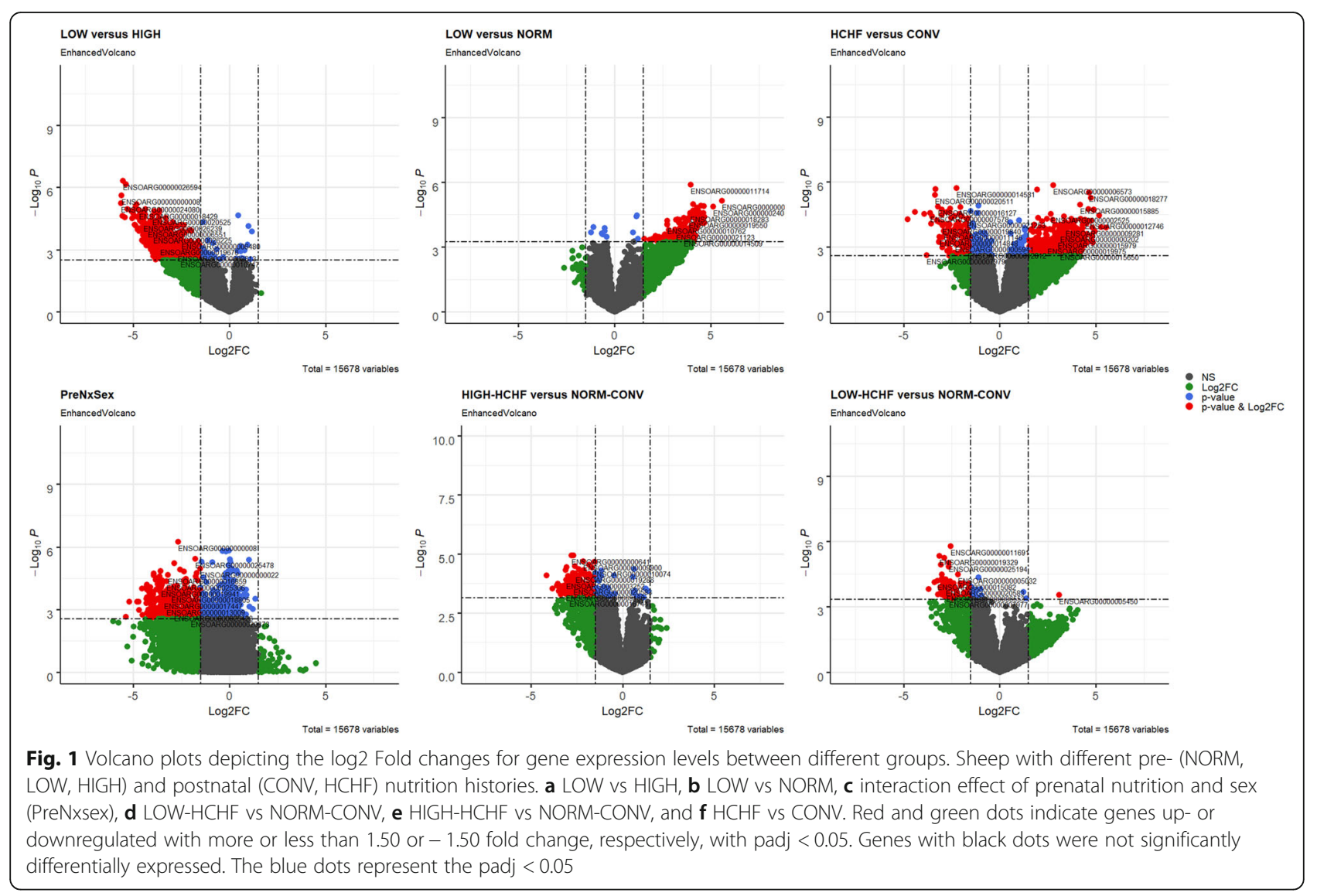

Besides the selection of hub genes, we also identifed the top signifcant modules (sub-cluster) through the PPI networks analysis, of which modules having more than 6 nodes (genes) were selected. Two top modules were identified from the PPI network of the DEGs for LOW vs HIGH: module 1 with MCODE score $=9.40$ with 11 nodes and 47 edges, and module 2 with MCODE score $=$ 6.00 with 6 nodes and 15 edges. Two top significant modules were also observed for PreNxsex: module 1 with MCODE score $=9.56$ with 10 nodes and 43 edges, and module 2 with MCODE score $=6.00$ with 6 nodes and 15 edges. One significant module was identified for LOW-HCHF vs NORM-CONV (7 nodes and 20 edges), HIGH-HCHF vs NORM-CONV (8 nodes and 26 edges) and $\mathrm{HCHF}$ vs CONV (6 nodes and 14 edges) with MCODE scores of $6.67,7.43$ and 5.60 , respectively, as shown in Fig. 3a-g. No significant modules were observed for LOW vs NORM.

To gain insight into the biological function of these modules, a functional enrichment analysis was performed with ClueGO. For LOW vs HIGH, module 1 was enriched in the group terms 'attachment of mitotic spindle microtubules to kinetochore' (74.47\%), 'mitotic sister chromatid segregation' (21.28\%), 'mitotic nuclear division' (2.13\%) and 'mitotic spindle organization' $(2.13 \%)$, whereas module 2 was enriched in 'oxidoreductase activity, acting on $\mathrm{NAD}(\mathrm{P}) \mathrm{H}$, quinone or similar compound as receptor' (93.33\%) and 'oxidoreductase phosphorylation' (6.67\%). For the PreNxsex interaction, no functional enrichment was found for module 1, but similar to LOW vs $\mathrm{HIGH}$, module 2 was enriched in 'oxidoreductase activity, acting on $\mathrm{NAD}(\mathrm{P}) \mathrm{H}$, quinone or similar compound as receptor' (93.33\%) and 'oxidoreductase phosphorylation' (6.67\%). Both the LOW-HCHF and HIGH-HCHF vs NORM-CONV module was enriched in 'myeloid leukocyte activation' (100\%). For HCHF vs CONV, the significant module was enriched in 'collecting duct acid secretion' (88.24\%), 'proton-transporting V-type ATPase complex' (5.88\%), and 'proton-transporting twosector ATPase complex' (5.88\%).

Functional enrichment analyses of differentially expressed genes (DEGs)

DEGs of prenatal nutrition and prenatal $x$ sex (PreNxsex)

The list of the most significant term of a group (leading term) for all comparison are shown in Table 4. Functional 
Table 2 The top 10 known up- and downregulated DEGs for the six (A-F) group comparisons

\begin{tabular}{|c|c|c|c|c|c|}
\hline Gene symbol & $\log 2 \mathrm{FC}$ & $P$-value & padj & Encoded protein & Expression \\
\hline \multicolumn{6}{|c|}{ A) LOW vs HIGH } \\
\hline DSCAM & -5.460 & 2.84E-05 & 0.015 & Down Syndrome Cell Adhesion Molecule & down \\
\hline C10orf71 & -5.395 & 7.26E-07 & 0.006 & Chromosome 10 Open Reading Frame 71 & down \\
\hline TMEM63C & -5.120 & $1.42 \mathrm{E}-05$ & 0.015 & Transmembrane Protein 63C & down \\
\hline FAM221A & -4.924 & $6.54 \mathrm{E}-05$ & 0.015 & Family With Sequence Similarity 221 Member A & down \\
\hline ADAM7 & -4.889 & $1.08 \mathrm{E}-05$ & 0.0149 & ADAM Metallopeptidase Domain 7 & down \\
\hline STRC & -4.876 & 7.30E-05 & 0.016 & Stereocilin & down \\
\hline TKTL1 & -4.824 & $6.83 \mathrm{E}-06$ & 0.015 & Transketolase Like 1 & down \\
\hline CYP24A1 & -4.770 & 0.0001 & 0.0167 & Cytochrome P450 Family 24 Subfamily A Member 1 & down \\
\hline MYT1 & -4.708 & 0.0001 & 0.017 & Myelin Transcription Factor 1 & down \\
\hline ARHGEF5 & -4.703 & 1.30E-05 & 0.015 & Rho Guanine Nucleotide Exchange Factor 5 & down \\
\hline ETFRF1 & 0.997 & 7.44E-05 & 0.015 & Electron Transfer Flavoprotein Regulatory Factor 1 & up \\
\hline H1-O & 0.947 & 0.0006 & 0.023 & H1.0 Linker Histone & up \\
\hline CHCHD1 & 0.790 & 0.001 & 0.028 & Coiled-Coil-Helix-Coiled-Coil-Helix Domain Containing 1 & up \\
\hline PECR & 0.689 & 0.003 & 0.048 & Peroxisomal Trans-2-Enoyl-CoA Reductase & up \\
\hline FBXO6 & 0.685 & 0.001 & 0.027 & F-Box Protein 6 & up \\
\hline ARL2 & 0.642 & 0.003 & 0.044 & ADP Ribosylation Factor Like GTPase 2 & up \\
\hline MRPL20 & 0.625 & 0.0007 & 0.024 & Mitochondrial Ribosomal Protein L20 & up \\
\hline WARS1 & 0.576 & 0.001 & 0.030 & Tryptophanyl-TRNA Synthetase 1 & up \\
\hline PSMB9 & 0.574 & 0.0007 & 0.023 & Proteasome 205 Subunit Beta 9 & up \\
\hline SNAPIN & 0.560 & 0.003 & 0.046 & SNAP Associated Protein & up \\
\hline \multicolumn{6}{|c|}{ B) LOW vs NORM } \\
\hline CADM1 & -1.234 & 0.0002 & 0.041 & Cell Adhesion Molecule 1 & down \\
\hline CXCR4 & -1.097 & 0.0001 & 0.036 & C-X-C Motif Chemokine Receptor 4 & down \\
\hline VRK2 & -0.678 & 0.0002 & 0.042 & VRK Serine/Threonine Kinase 2 & down \\
\hline GXYLT1 & -0.617 & 0.0003 & 0.043 & Glucoside Xylosyltransferase 1 & down \\
\hline SELENOI & -0.519 & 0.0002 & 0.039 & Selenoprotein I & down \\
\hline TRMT13 & -0.511 & 0.0001 & 0.036 & TRNA Methyltransferase 13 Homolog & down \\
\hline PIKFYVE & -0.419 & 0.0004 & 0.043 & $\begin{array}{l}\text { Phosphoinositide Kinase, FYVE-Type Zinc Finger } \\
\text { Containing }\end{array}$ & down \\
\hline FSIP2 & 4.677 & 4.09E-05 & 0.026 & Fibrous Sheath Interacting Protein 2 & up \\
\hline$X D H$ & 4.661 & 7.57E-05 & 0.030 & Xanthine Dehydrogenase & up \\
\hline $\mathrm{IQCH}$ & 4.631 & 1.33E-05 & 0.026 & IQ Motif Containing H & up \\
\hline DCST1 & 4.630 & 8.15E-05 & 0.031 & DC-STAMP Domain Containing 1 & up \\
\hline LIPN & 4.557 & 3.09E-05 & 0.026 & Lipase Family Member N & up \\
\hline CSMD3 & 4.452 & $6.03 \mathrm{E}-05$ & 0.027 & CUB And Sushi Multiple Domains 3 & up \\
\hline$A B C A 12$ & 4.450 & 4.66E-05 & 0.026 & ATP Binding Cassette Subfamily A Member 12 & up \\
\hline RNF17 & 4.409 & 3.85E-05 & 0.026 & Ring Finger Protein 17 & up \\
\hline ANO4 & 4.370 & $9.46 \mathrm{E}-05$ & 0.032 & Anoctamin 4 & up \\
\hline CPN1 & 4.323 & $3.01 \mathrm{E}-05$ & 0.026 & Carboxypeptidase N Subunit 1 & up \\
\hline \multicolumn{6}{|l|}{ C) PreNxsex } \\
\hline TEX11 & -5.219 & 0.0004 & 0.023 & Testis Expressed 11 & down \\
\hline FAT2 & -4.728 & 0.0004 & 0.023 & FAT Atypical Cadherin 2 & down \\
\hline FSIP2 & -4.695 & 0.001 & 0.034 & Fibrous Sheath Interacting Protein 2 & down \\
\hline
\end{tabular}


Table 2 The top 10 known up- and downregulated DEGs for the six (A-F) group comparisons (Continued)

\begin{tabular}{|c|c|c|c|c|c|}
\hline Gene symbol & $\log 2 \mathrm{FC}$ & $P$-value & padj & Encoded protein & Expression \\
\hline CCDC180 & -4.534 & 0.002 & 0.042 & Coiled-Coil Domain Containing 180 & down \\
\hline $\mathrm{ROBO}$ & -4.324 & 0.0005 & 0.024 & Roundabout Guidance Receptor 3 & down \\
\hline LIPN & -4.319 & 8.00E-05 & 0.018 & Lipase Family Member N & down \\
\hline$A B C A 12$ & -4.286 & 0.0001 & 0.018 & ATP Binding Cassette Subfamily A Member 12 & down \\
\hline CNTNAP5 & -4.220 & 0.002 & 0.042 & Contactin Associated Protein Family Member 5 & down \\
\hline CSMD3 & -4.194 & 0.0001 & 0.018 & CUB And Sushi Multiple Domains 3 & down \\
\hline SLC26A5 & -4.157 & 0.0001 & 0.018 & Solute Carrier Family 26 Member 5 & down \\
\hline ANKS $4 B$ & 1.046 & 0.0007 & 0.029 & Ankyrin Repeat And Sterile Alpha Motif Domain Containing 4B & up \\
\hline EPHA2 & 0.880 & 0.0002 & 0.019 & EPH Receptor A2 & up \\
\hline PTMA & 0.820 & 0.0002 & 0.020 & Prothymosin Alpha & up \\
\hline BTBD19 & 0.767 & 0.0002 & 0.019 & BTB Domain Containing 19 & up \\
\hline EGR2 & 0.660 & 0.001 & 0.036 & Early Growth Response 2 & up \\
\hline FBRS & 0.630 & 0.0001 & 0.018 & FAU Ubiquitin Like And Ribosomal Protein S30 Fusion & up \\
\hline MAPK8IP3 & 0.588 & 0.0006 & 0.026 & Mitogen-Activated Protein Kinase 8 Interacting Protein 3 & up \\
\hline PLEKHG2 & 0.568 & 0.001 & 0.036 & Pleckstrin Homology And RhoGEF Domain Containing G2 & up \\
\hline SYNDIG1L & 0.567 & 0.0003 & 0.021 & Synapse Differentiation Inducing 1 Like & up \\
\hline ARSL & 0.560 & 0.0003 & 0.022 & Arylsulfatase $L$ & up \\
\hline \multicolumn{6}{|c|}{ D) LOW-HCHF vs NORM-CONV } \\
\hline LIPA & -3.246 & $6.49 \mathrm{E}-05$ & 0.040 & Lipase A, Lysosomal Acid Type & down \\
\hline FN1 & -3.124 & $4.58 \mathrm{E}-06$ & 0.021 & Fibronectin 1 & down \\
\hline ITGB2 & -3.094 & 0.0001 & 0.040 & Integrin Subunit Beta 2 & down \\
\hline LGALS3 & -3.054 & $1.21 \mathrm{E}-05$ & 0.031 & Galectin 3 & down \\
\hline MSR1 & -3.035 & 0.0002 & 0.041 & Macrophage Scavenger Receptor 1 & down \\
\hline MS4A8 & -3.025 & 0.0002 & 0.041 & Membrane Spanning 4-Domains A8 & down \\
\hline$\angle C P 1$ & -3.029 & $5.66 \mathrm{E}-05$ & 0.040 & Lymphocyte Cytosolic Protein 1 & down \\
\hline CAPG & -3.020 & 0.0002 & 0.044 & Capping Actin Protein, Gelsolin Like & down \\
\hline CTSZ & -3.011 & 3.40E-05 & 0.040 & Cathepsin Z & down \\
\hline C5AR1 & -2.985 & 0.0002 & 0.040 & Complement C5a Receptor 1 & down \\
\hline$F|B| N$ & 1.384 & 0.0004 & 0.048 & Fin Bud Initiation Factor Homolog & up \\
\hline \multicolumn{6}{|c|}{ E) HIGH-HCHF vs NORM-CONV } \\
\hline$A C H E$ & -4.150 & $8.08 \mathrm{E}-05$ & 0.033 & Acetylcholinesterase (Cartwright Blood Group) & down \\
\hline ST14 & -3.840 & 0.0003 & 0.038 & ST14 Transmembrane Serine Protease Matriptase & down \\
\hline PADI2 & -3.548 & 0.0002 & 0.036 & Peptidyl Arginine Deiminase 2 & down \\
\hline CRLF2 & -3.385 & 0.0005 & 0.044 & Cytokine Receptor Like Factor 2 & down \\
\hline HTRA4 & -3.358 & 0.0002 & 0.036 & HtrA Serine Peptidase 4 & down \\
\hline CD300E & -3.210 & 0.0004 & 0.040 & CD300e Molecule & down \\
\hline S100A5 & -3.211 & 0.0004 & 0.041 & S100 Calcium Binding Protein A5 & down \\
\hline NLRP1 & -3.117 & 4.80E-05 & 0.033 & NLR Family Pyrin Domain Containing 1 & down \\
\hline HK3 & -3.100 & 0.0001 & 0.033 & Hexokinase 3 & down \\
\hline ITGAX & -3.084 & 0.0004 & 0.040 & Integrin Subunit Alpha X & down \\
\hline$F|B| N$ & 1.380 & 0.0004 & 0.040 & Fin Bud Initiation Factor Homolog & up \\
\hline HMCN1 & 1.269 & 0.0003 & 0.038 & Hemicentin 1 & up \\
\hline ETNPPL & 0.990 & 0.0006 & 0.047 & Ethanolamine-Phosphate Phospho-Lyase & up \\
\hline ARHGAP2O & 0.837 & 0.0006 & 0.047 & Rho GTPase Activating Protein 20 & up \\
\hline
\end{tabular}


Table 2 The top 10 known up- and downregulated DEGs for the six (A-F) group comparisons (Continued)

\begin{tabular}{|c|c|c|c|c|c|}
\hline Gene symbol & $\log 2 \mathrm{FC}$ & $P$-value & padj & Encoded protein & Expression \\
\hline DHRS12 & 0.780 & 0.0006 & 0.047 & Dehydrogenase/Reductase 12 & up \\
\hline LYRM1 & 0.740 & 0.0006 & 0.047 & LYR Motif Containing 1 & up \\
\hline TRIM13 & 0.593 & 0.0004 & 0.041 & Tripartite Motif Containing 13 & up \\
\hline DNAL1 & 0.589 & 0.0005 & 0.042 & Dynein Axonemal Light Chain 1 & up \\
\hline PDRG1 & 0.564 & $9.18 \mathrm{E}-05$ & 0.033 & P53 And DNA Damage Regulated 1 & up \\
\hline \multicolumn{6}{|c|}{ F) HCHF vs CONV } \\
\hline SPP1 & -4.788 & 5.45E-05 & 0.021 & Secreted Phosphoprotein 1 & down \\
\hline GPNMB & -4.412 & $2.55 \mathrm{E}-05$ & 0.019 & Glycoprotein Nmb & down \\
\hline TREM2 & -3.924 & 3.08E-05 & 0.019 & Triggering Receptor Expressed On Myeloid Cells 2 & down \\
\hline SCIN & -3.612 & $2.75 \mathrm{E}-05$ & 0.019 & Scinderin & down \\
\hline LIPA & -3.528 & 3.99E-05 & 0.020 & Lipase A, Lysosomal Acid Type & down \\
\hline CAPG & -3.374 & 4.07E-06 & 0.010 & Capping Actin Protein, Gelsolin Like & down \\
\hline S100A4 & -3.350 & 2.19E-06 & 0.009 & 100 Calcium Binding Protein A4 & down \\
\hline TYROBP & -3.248 & $6.54 \mathrm{E}-05$ & 0.021 & Transmembrane Immune Signaling Adaptor TYROBP & down \\
\hline CTSZ & -3.211 & $1.38 \mathrm{E}-05$ & 0.019 & Cathepsin Z & down \\
\hline MMP9 & -3.170 & 0.0006 & 0.034 & Matrix Metallopeptidase 9 & down \\
\hline LIPN & 5.163 & 3.63E-05 & 0.020 & Lipase Family Member N & up \\
\hline DCST1 & 4.950 & 0.0002 & 0.027 & DC-STAMP Domain Containing 1 & up \\
\hline TEX11 & 4.896 & $1.88 \mathrm{E}-05$ & 0.019 & Testis Expressed 11 & up \\
\hline$A B C B 5$ & 4.823 & 0.0003 & 0.028 & ATP Binding Cassette Subfamily B Member 5 & up \\
\hline CCDC148 & 4.808 & 0.0001 & 0.023 & Coiled-Coil Domain Containing 148 & up \\
\hline FSIP2 & 4.802 & 0.0003 & 0.028 & Fibrous Sheath Interacting Protein 2 & up \\
\hline C6orf58 & 4.796 & 0.0004 & 0.030 & Chromosome 6 Open Reading Frame 58 & up \\
\hline MORC1 & 4.780 & 0.0006 & 0.033 & MORC Family CW-Type Zinc Finger 1 & up \\
\hline DKK1 & 4.776 & $6.43 \mathrm{E}-05$ & 0.021 & Dickkopf WNT Signaling Pathway Inhibitor 1 & up \\
\hline CD28 & 4.642 & $3.12 \mathrm{E}-06$ & 0.010 & CD28 Molecule & up \\
\hline
\end{tabular}

enrichment analyses revealed that GO terms, significantly enriched with genes differentially expressed between LOW vs HIGH and LOW vs NORM, were predominantly related to transmembrane (ion) transport activities, motor activities related to cytoskeletal and spermatozoa function (microtubules and the cytoskeletal motor protein, dynein), and responsiveness to the (micro) environmental extracellular conditions, including endocrine and nervous stimuli (Table 4). There were, however, specific terms, which distinguished LOW vs HIGH and not LOW vs NORM and vice versa. Thus, the term 'positive regulation of vascular endothelial growth' was enriched with DEGs between LOW vs $\mathrm{HIGH}$, whereas the terms 'homophilic adhesion via plasma molecules (cellular adhesion)' and 'lipid transporter activity' were enriched with DEGs between LOW vs NORM.

\section{DEGs of postnatal nutrition and interaction of prenatal and} postnatal nutrition

Most of the functional enrichment in relation to the early postnatal HCHF feeding were involved in immunity-related processes and pathways as well as transmembrane (ion) transport. Besides that, a biological process related to cell differentiation involved in kidney development was enriched among the downregulated DEGs in HCHF sheep.

In particular, 100 out of 101 and 180 out of 192 genes were downregulated in LOW-HCHF and HIGH-HCHF compared to NORM-CONV, respectively. The downregulated genes identified in both group contrasts (LOW-HCHF or HIGHHCHF vs NORM-CONV) were associated with pathways involved in adipose tissue remodeling (stress response and apoptosis-related processes/pathways) and immunity-related processes/pathways. In addition, we found, the KEGG pathway related to 'Cholesterol metabolism' was enriched in LOW-HCHF compared to NORM-CONV, where the genes involved were downregulated in LOW-HCHF group.

\section{Discussion}

In this study, we aimed to reveal the biological mechanisms and pathways involved in and/or responsible for 
Table 3 The list of top 10 genes identified for six (A-F) group comparisons

\begin{tabular}{|c|c|c|c|c|c|c|c|}
\hline Gene & Degree & Gene & EcCentricity & Gene & EPC & Gene & MNC \\
\hline \multicolumn{8}{|l|}{ A) LOW vs HIGH } \\
\hline$T T K$ & 15 & MELK & 0.009771 & TTK & 11.523 & TTK & 14 \\
\hline$A \cup R K B$ & 14 & PBK & 0.009771 & $M L P H$ & 11.41 & $A \cup R K B$ & 13 \\
\hline$N D C 80$ & 13 & ESCO2 & 0.009771 & NDC80 & 11.369 & NDC80 & 13 \\
\hline AURKA & 13 & NDC80 & 0.009771 & AURKA & 11.362 & AURKA & 13 \\
\hline KIF2C & 12 & AURKA & 0.009771 & KIF2C & 11.282 & KIF2C & 12 \\
\hline MELK & 11 & EXO1 & 0.009771 & PBK & 11.094 & MELK & 11 \\
\hline$P B K$ & 11 & POLE & 0.009771 & MELK & 10.921 & PBK & 11 \\
\hline EXO1 & 10 & $T T K$ & 0.009771 & CENPN & 10.474 & CENPN & 9 \\
\hline CCDC39 & 9 & CLSPN & 0.009771 & $A S F 1 B$ & 9.639 & EXO1 & 8 \\
\hline CENPN & 9 & CCDC39 & 0.007892 & EXO1 & 9.508 & $A S F 1 B$ & 7 \\
\hline \multicolumn{8}{|l|}{ B) LOW vs NORM } \\
\hline$C C D C 39$ & 3 & $C C D C 39$ & 0.024242 & $C C D C 39$ & 2.394 & NIPAL4 & 1 \\
\hline TKTL1 & 2 & TKTL1 & 0.018182 & RIMS2 & 1.932 & $\mathrm{RPH} 3 \mathrm{~A}$ & 1 \\
\hline RIMS2 & 2 & RIMS2 & 0.018182 & TKTL1 & 1.923 & $C C D C 39$ & 1 \\
\hline NIPAL4 & 1 & NIPAL4 & 0.012121 & HYDIN & 1.912 & $H K D C 1$ & 1 \\
\hline $\mathrm{RPH} 3 \mathrm{~A}$ & 1 & $\mathrm{RPH} 3 \mathrm{~A}$ & 0.012121 & DNAH11 & 1.899 & $\pi N$ & 1 \\
\hline$H K D C 1$ & 1 & $\pi N$ & 0.012121 & ARMC4 & 1.869 & HHIP & 1 \\
\hline$\pi T N$ & 1 & $H H I P$ & 0.012121 & CNTNAP5 & 1.696 & CNTNAP5 & 1 \\
\hline HHIP & 1 & $\mathrm{ROBO3}$ & 0.012121 & PCLO & 1.68 & $\mathrm{ROBO}$ & 1 \\
\hline CNTNAP5 & 1 & USH2A & 0.012121 & TEX11 & 1.679 & USH2A & 1 \\
\hline $\mathrm{ROBO} 3$ & 1 & ARMC4 & 0.012121 & $H K D C 1$ & 1.666 & TKTL1 & 1 \\
\hline \multicolumn{8}{|l|}{ C) CPreNxsex } \\
\hline WDFY1 & 27 & BTAF1 & 0.016998 & CDC5L & 38.608 & ENSOARG00000019688 & 10 \\
\hline ENSOARG00000019688 & 11 & CDC5L & 0.014873 & ENSOARG00000010203 & 35.73 & RSL24D1 & 10 \\
\hline NMD3 & 10 & GTF2B & 0.014873 & RSL24D1 & 34.388 & ENSOARG00000008494 & 9 \\
\hline PRKACB & 10 & CDKN2AIPNL & 0.013221 & ENSOARG00000019688 & 34.338 & SRP54 & 9 \\
\hline SRP54 & 10 & ENSOARG00000010203 & 0.013221 & SRP54 & 34.311 & ENSOARG00000001638 & 9 \\
\hline ENSOARG00000008494 & 9 & TMPO & 0.013221 & ENSOARG00000008494 & 34.285 & ENSOARG00000011629 & 9 \\
\hline ENSOARG00000001638 & 9 & PRPF39 & 0.013221 & ENSOARG00000016333 & 34.274 & ENSOARG00000006781 & 9 \\
\hline ENSOARG00000011629 & 9 & HNRNPC & 0.013221 & RPL37 & 34.25 & LOC780467 & 9 \\
\hline ENSOARG00000006781 & 9 & TCEA1 & 0.013221 & ENSOARG00000001638 & 34.249 & ENSOARG00000016333 & 9 \\
\hline LOC780467 & 9 & MSH6 & 0.013221 & LOC780467 & 34.226 & RPL37 & 8 \\
\hline \multicolumn{8}{|c|}{ D) LOW-HCHF vs NORM-CONV } \\
\hline ITGB2 & 11 & CTSS & 0.062706 & ITGB2 & 8.034 & ITGB2 & 10 \\
\hline CTSS & 9 & PTPN6 & 0.062706 & C1QB & 7.933 & CTSS & 9 \\
\hline$C 1 Q B$ & 9 & CSF1R & 0.062706 & CTSS & 7.817 & CSF1R & 8 \\
\hline CSF1R & 8 & ITGB2 & 0.062706 & CSF1R & 7.756 & $C 1 Q B$ & 8 \\
\hline TYROBP & 8 & C5AR1 & 0.04703 & TYROBP & 7.662 & SPI1 & 8 \\
\hline SPI1 & 8 & C1QA & 0.04703 & SPI1 & 7.568 & C1QA & 7 \\
\hline$C 1 Q A$ & 7 & $C Y B B$ & 0.04703 & $C 1 Q A$ & 7.427 & TYROBP & 7 \\
\hline LAPTM5 & 7 & LAPTM5 & 0.04703 & LAPTM5 & 7.275 & LAPTM5 & 6 \\
\hline PTPN6 & 4 & FN1 & 0.04703 & PTPN6 & 5.573 & C5AR1 & 3 \\
\hline C5AR1 & 3 & $C 1 Q B$ & 0.04703 & C5AR1 & 5.306 & PTPN6 & 3 \\
\hline
\end{tabular}


Table 3 The list of top 10 genes identified for six (A-F) group comparisons (Continued)

\begin{tabular}{|c|c|c|c|c|c|c|c|}
\hline Gene & Degree & Gene & EcCentricity & Gene & EPC & Gene & MNC \\
\hline \multicolumn{8}{|c|}{ E) HIGH-HCHF vs NORM-CONV } \\
\hline ITGB2 & 17 & CIQA & 0.038743 & ITGB2 & 13.878 & ITGB2 & 13 \\
\hline TYROBP & 12 & LAPTM5 & 0.038743 & $C 1 Q B$ & 13.461 & CTSS & 10 \\
\hline CTSS & 11 & CTSS & 0.038743 & TYROBP & 13.449 & $C 1 Q B$ & 10 \\
\hline$C 1 Q B$ & 10 & CSF1R & 0.038743 & CTSS & 13.19 & CSF1R & 9 \\
\hline CSF1R & 9 & C1QC & 0.038743 & CSF1R & 13.163 & TYROBP & 9 \\
\hline$S P I 1$ & 9 & $C 1 Q B$ & 0.038743 & C1QA & 12.963 & $S P I 1$ & 9 \\
\hline$C 1 Q A$ & 8 & ITGB2 & 0.038743 & SPI1 & 12.862 & C1QA & 8 \\
\hline LAPTM5 & 8 & FCER1G & 0.038743 & C1QC & 12.328 & C1QC & 7 \\
\hline C1QC & 7 & TYROBP & 0.03874 & LAPTM5 & 11.808 & LAPTM5 & 6 \\
\hline PTPN6 & 5 & SPI1 & 0.03874 & PTPN6 & 9.368 & C5AR1 & 3 \\
\hline \multicolumn{8}{|c|}{ F) HCHF vs CONV } \\
\hline TYROBP & 10 & MMP9 & 0.010243 & TYROB & 13.307 & ATP6V1B2 & 6 \\
\hline CXCR4 & 8 & CD44 & 0.010243 & $I T G B$ & 12.993 & ATP6AP2 & 5 \\
\hline ATP6V1B & 6 & CXCR4 & 0.008536 & CTS & 12.632 & ATP6V1C1 & 5 \\
\hline PTPN & 6 & TGFB1 & 0.008536 & PTPN6 & 12.551 & TCIRG1 & 5 \\
\hline CCDC39 & 6 & CD28 & 0.008536 & $C X C R$ & 12.201 & ATP6VIE1 & 5 \\
\hline PKM & 6 & $C Y B B$ & 0.008536 & MMP9 & 12.1 & ATP6V1A & 4 \\
\hline MMP9 & 6 & ALCAM & 0.008536 & LAPTM5 & 11.938 & CTSS & 4 \\
\hline ITGB2 & 6 & ENSOARG0000000780 & 0.008536 & CD44 & 11.692 & MMP9 & 4 \\
\hline TCIRG1 & 6 & SPP1 & 0.008536 & ZAP70 & 11.335 & ITGB2 & 4 \\
\hline ATP6V1A & 5 & ACTN2 & 0.007682 & $C Y B B$ & 10.239 & ENTPD5 & 3 \\
\hline
\end{tabular}

The top 10 genes were identified according to four different criteria (Degree, EcCentricity, EPC and MNC) through the protein-protein interaction (PPI). Significant hub genes are highlighted in bold

tissue-specific (SUB and PER) responses to early life malnutrition, and to identify potential biomarkers (hub genes) by Next-Generation Sequencing transcriptomic analysis underlying these changes and their possible association to adverse metabolic and kidney developmental traits. We have previously demonstrated, in the sheep providing samples for this study, that SUB of adult sheep irrespective of their early life nutrition history, had similar upper limits for expandability, however with greater expandability capacity in females than males, whereas PER was a major target of early life nutritional programming, and a determinant for intra-abdominal fat distribution patterns [15]. Adult males that had been exposed to late gestation LOW level of nutrition followed by the mismatching HCHF diet in early postnatal life, had reduced hypertrophic capacity of PER, whereas fetally overnourished (HIGH) males apparently were resistant to this effect of the HCHF diet, and all HIGH sheep had increased PER hypertrophic expandability similar to what was observed in female sheep [15]. As previously mentioned, morphological features of SUB and PER were poorly correlated to changes in gene expression of well-known markers for adipose development, metabolism, angiogenesis and inflammation. Finally, the adult LOW-HCHF sheep, irrespective of sex, were hypercholesterolemic, hyperureaemic and hypercreatinaemic compared to all other groups, despite a preceding 2years period of dietary correction after the exposure to the HCHF diet in early postnatal life $[16,17]$, and by the end of the exposure to the HCHF diet, the 6-months old HCHF lambs had massive deposition of fat in PER coexisting with a $1 / 3$ reduction in kidney size [17].

In the present part of the study, we found gene expression profiles of PER, but not SUB were modulated by late gestation and early postnatal nutrition, and the latter even after the same low-fat hay-based diet had been fed to all sheep for 2 years. Irrespective of early life nutrition, only sex-specific differences in the expression of 44 mRNA were identified for SUB. Unsurprisingly, longterm effects of the pre-and postnatal nutrition were observed for mRNA expression of PER, especially as a consequence of a prenatal LOW level of nutrition. The majority (more than half) of DEGs identified in LOW were downregulated when compared to HIGH but in 


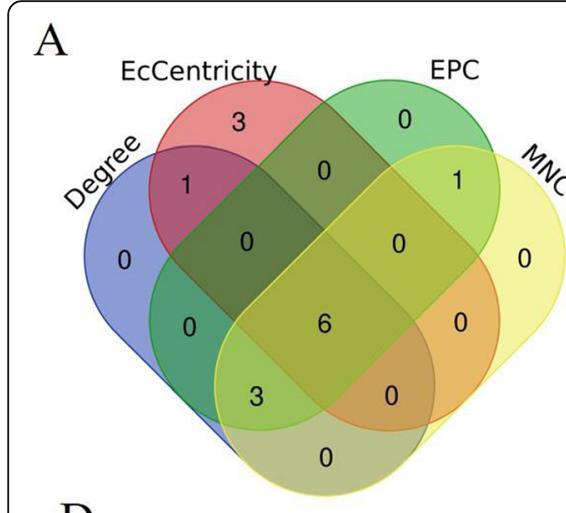

$\mathrm{D}$

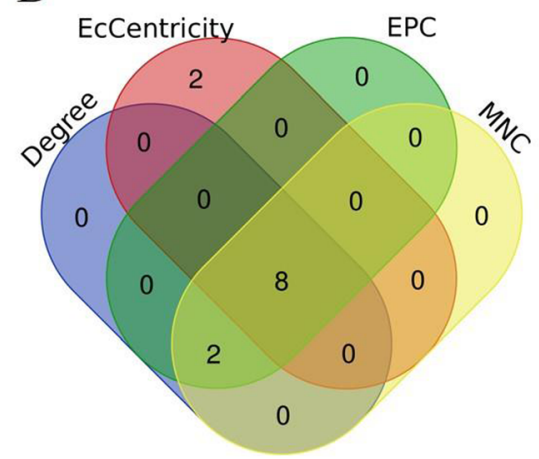

B

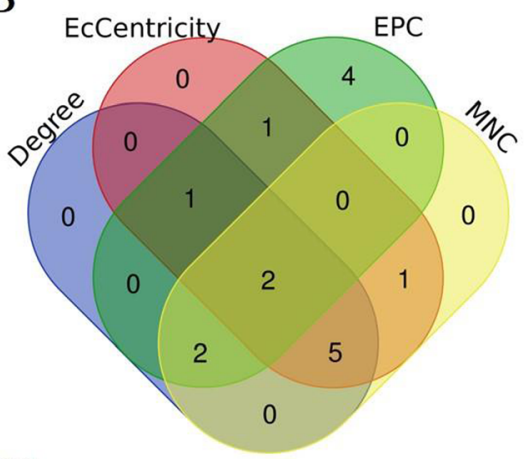

E

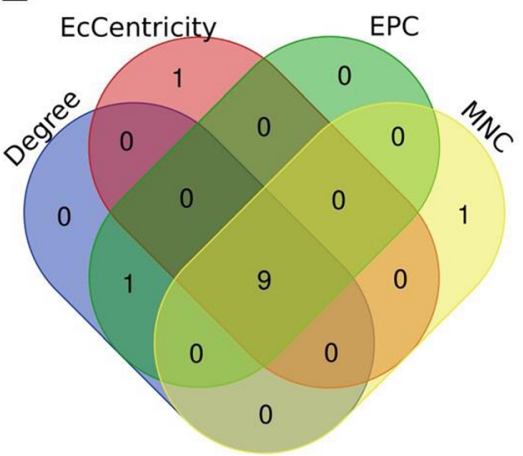

$\mathrm{C}$

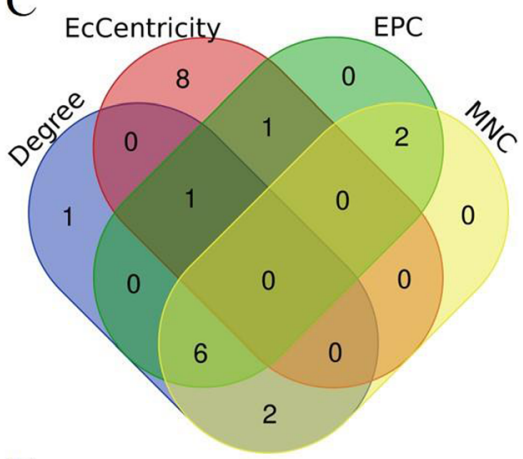

$\mathrm{F}$

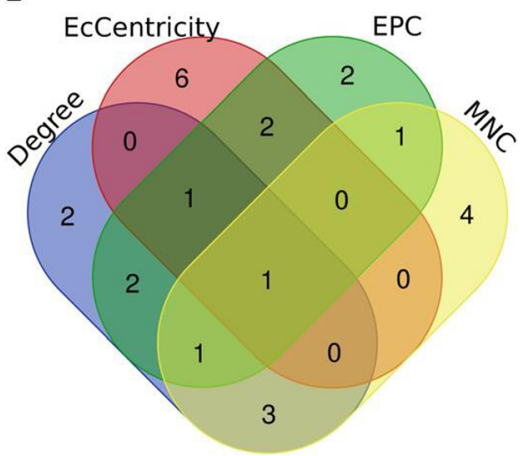

Fig. 2 Venn diagram showing the number of top 10 ranked genes and hub genes. The hub genes were identified (genes overlapped in the four centrality methods) in the following comparisons: a LOW vs HIGH, b LOW vs NORM, c interaction between prenatal nutrition and sex (PreNxsex), d LOW-HCHF vs NORM-CONV, e HIGH-HCHF vs NORM-CONV, and $\mathbf{f}$ HCHF vs CONV. For the selection of hub genes, the PPI networks were first constructed using the DEGs with a high-confidence score $<0.70$, followed by selection of top 10 ranked DEGs based on four centrality methods: Degree, EcCentrity, EPC, and MNC performed in the CytoHubba application (Cytoscape-plug in). Finally, genes that fell within all of these four criteria were considered as hub genes

contrast opposite response was observed when compared to NORM (upregulated). The expression of DEGs between LOW/HIGH-HCHF and NORM-CONV were mostly downregulated, and only very few (less than 13) were upregulated in the former groups.

\section{The mRNA expression profiles of SUB in adult sheep were unaffected by the late gestation and early postnatal nutrition history}

It is well-known that fat distribution patterns differ between males and females, with females accruing more fat in subcutaneous and gluteofemoral regions, whereas males have higher preference for lipid accumulation in the intraabdominal area. It has been suggested that the greater susceptibility for central adiposity in males is linked to a higher predisposition for insulin resistance and cardiovascular diseases [10, 24, 25]. In contrast, both subcutaneous and gluteofemoral fat serves a protective role in this respect by preventing abdominal and ectopic fat (non-adipose tissues) depositions and associated adverse effects [7, 9].

We have recently shown in our sheep model of early life malnutrition that there was a marked reduction in intrinsic, non-obese cellularity in SUB in prenatally under- and overnourished (LOW and HIGH) adolescent lambs (6-months of age), but this difference was not evident in the adult sheep (2.5-years old). These findings suggest there must have been a time window for compensatory hyperplastic growth in this tissue, which was not related to the development of obesity $[15,26]$. Moreover, in both lambs and adult sheep, and irrespective of the early life nutrition history, there was an upper-limit for hypertrophic expandability in subcutaneous adipocytes, with greater expansion capacity in females than males $[15,26]$, and this has also been observed in humans and murine model [13, 27, 28]. The lack of differences in mRNA expression in SUB of the adult sheep exposed to different combinations of nutrition in early life is consistent with these previous observations, and upper-limits for expandability in SUB do therefore not appear to be subject to late gestation programming. The present study could not contribute to shed light on the underlying mechanisms (e.g. molecular and pathways) that enabled sheep previously exposed to LOW or HIGH levels of nutrition in prenatal life to restore their hyperplastic ability from adolescence to adulthood. This warrants further studies. 


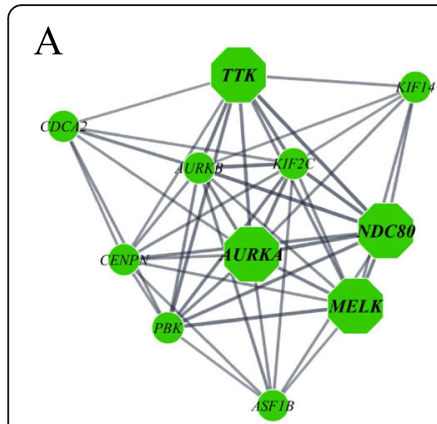

MCODE score $=9.40$

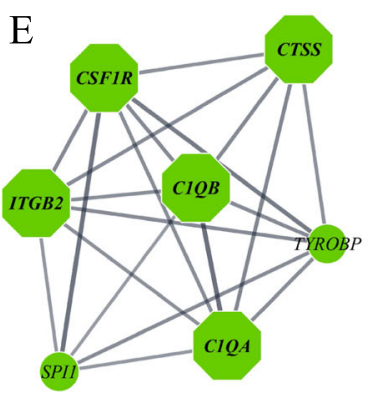

MCODE score $=6.67$

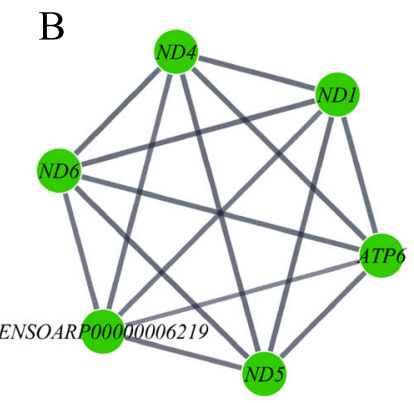

MCODE score $=6.00$

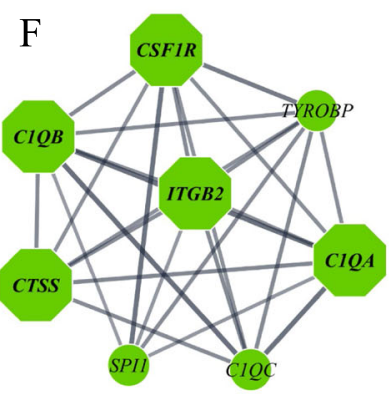

MCODE score $=7.43$

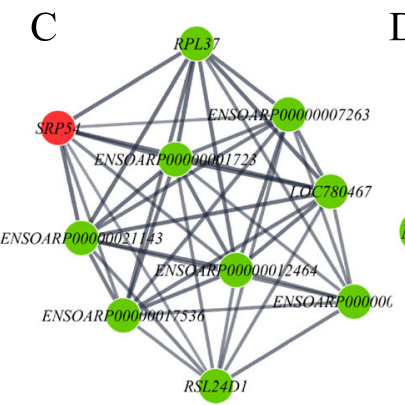

MCODE score $=9.56$

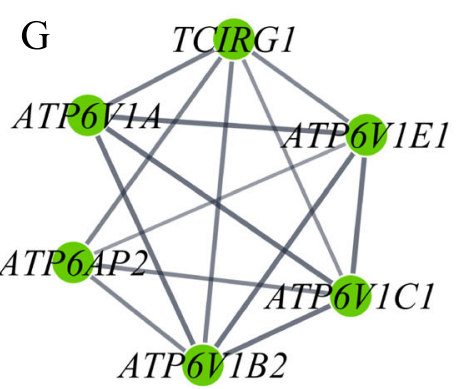

MCODE score $=5.6$

Fig. 3 a-g The significant modules from PPI networks. $\mathbf{a}-\mathbf{b}$ module 1 and module 2 for LOW vs HIGH, c-d module 1 and module 2 for interaction of prenatal nutrition and sex (PreNxsex), e module for LOW-HCHF vs NORM-CONV, f module for HIGH-HCHF vs NORM-CONV, and $\mathbf{g}$ module for HCHF vs CONV. The green and red nodes represent downregulated and upregulated genes, respectively, and the octagon nodes represent hub genes within the hub genes within the specific modules

Nonetheless, as reported previously, the restoration of hyperplastic ability in SUB in prenatally malnourished sheep might be due to a generally reported higher adipogenic capacity $[9,29-31]$.

Our results, also support the so-called adipose expandability theory, stating that once the fat storing capacity of SUB is exhausted upon continuous excess nutrient supply, fat deposition will be directed towards the intraabdominal region and ultimately towards non-adipocyte cell types, especially in males. SUB has thus been proposed as an initiating factor for the process of fat redistribution towards other anatomical sites, but not directly implicated in the development of obesity associated metabolic disturbances per se [27, 32-34]. As we have previously pointed out, the hitherto poorly studied PER thus becomes a major determinant for sex-specific intraabdominal partitioning of fat deposition towards the mesenteric adipose tissue and ectopic regions [15].

\section{The biological functions and pathways underlying the} long-term impacts of early nutrition on PER morphology and associated possible implications for metabolic disorders and kidney function

Very little scientific documentation exists on the role of PER (dys-)function in relation to obesity and related comorbidities. Due to its anatomical location, PER has been studied mostly by non-invasive means in humans, and the easily accessible epididymal adipose tissue has been the main visceral adipose tissue studied in rodents. Nonetheless, the effect of feeding a high-protein neonatal formula to the suckling pigs on PER morphological traits [35] and feeding of different energy and nutrient sources for growing pigs on the transcriptome profiles of PER [36] has been previously documented. However, to our knowledge the impact of prenatal nutrition on PER has not been studied in pig model. We have previously reported that early obesity development induced by the HCHF diet in our sheep model had significant longterm implications for PER, since massive PER expansion and adipocyte hypertrophy in 6-months old lambs was associated with a collapse of its subsequent expandability later in life in contrast to 2 other adipose tissues studied (SUB and mesenteric) [16, 23]. It was therefore intriguing, that the present part of the study revealed major long-term impacts of the early nutrition history on expression of genes in PER. To the best of our knowledge, we are the first to demonstrate that nutrition in both late gestation and early postnatal life can alter gene expression profiles permanently in PER in adulthood, even after animals had been fed the exact same low-fat diet for the last 2 years of their lives. Our results demonstrate that prenatal malnutrition (especially LOW), in a longterm, can alter expression of genes participating in basic cell biology/structural functions and pathways related to 
Table 4 Significantly enriched biological functions of the DEGs

\begin{tabular}{|c|c|c|c|}
\hline Group contrast & Ontology source & Biological function & Terms per group (\%) \\
\hline \multirow[t]{9}{*}{ A) LOW vs HIGH } & GO_Biological Process & transmembrane transport & 14.23 \\
\hline & GO_Molecular Function & ATP binding & 7.11 \\
\hline & GO_Biological Process & male gamete generation & 6.3 \\
\hline & GO_Cellular Component & presynapse & 5.89 \\
\hline & GO_Biological Process & ion channel activity & 5.08 \\
\hline & GO_Biological Process & regulation of macromolecule metabolic process & 6.67 \\
\hline & GO_Biological Process & ion transport & 3.05 \\
\hline & GO_Cellular Component & sodium channel complex & 2.89 \\
\hline & & others & 48.78 \\
\hline \multirow[t]{4}{*}{ B) LOW vs NORM } & GO_Biological Process & flagellated sperm motility & 38.46 \\
\hline & GO_Biological Process & inorganic anion transmembrane transport & 26.92 \\
\hline & GO_Cellular Component & postsynaptic density & 7.69 \\
\hline & & others & 26.93 \\
\hline \multirow{6}{*}{$\begin{array}{l}\text { C) Interaction effect of prenatal } \\
\text { nutrition and sex (PreNxsex) }\end{array}$} & GO_Cellular Component & dynein complex & 21.43 \\
\hline & GO_Biological Process & $\begin{array}{l}\text { inorganic molecular entity transmembrane } \\
\text { transporter activity }\end{array}$ & 20.00 \\
\hline & GO_Biological Process & cell development & 8.57 \\
\hline & GO_Biological Process & ion transmembrane transporter activity & 7.14 \\
\hline & GO_Molecular Function & motor activity & 7.14 \\
\hline & & others & 35.72 \\
\hline \multirow[t]{6}{*}{ D) LOW-HCHF vs NORM-CONV } & GO_Biological Process & leukocyte activation & 35.32 \\
\hline & GO_Biological Process & regulation of interleukin-6 production & 10.04 \\
\hline & GO_Molecular Function & cell adhesion molecule binding & 8.92 \\
\hline & GO_Biological Process & positive regulation of myeloid cell differentiation & 7.81 \\
\hline & KEGG & Cholesterol metabolism & 3.35 \\
\hline & & others & 34.56 \\
\hline \multirow[t]{6}{*}{ E) HIGH-HCHF vs NORM-CONV } & GO_Biological Process & leukocyte activation & 18.43 \\
\hline & GO_Biological Process & regulation of immune system process & 6.95 \\
\hline & GO_Biological Process & positive regulation of interleukin-1 production & 4.02 \\
\hline & GO_Biological Process & regulation of leukocyte mediated immunity & 3.15 \\
\hline & GO_Biological Process & positive regulation of leukocyte mediated immunity & 3.07 \\
\hline & & others & 64.38 \\
\hline \multicolumn{4}{|l|}{ F) HCHF vs CONV } \\
\hline \multirow[t]{4}{*}{ Upregulated } & GO_Biological Process & transmembrane transporter activity & 26.27 \\
\hline & GO_Biological Process & regulation of postsynaptic membrane potential & 9.91 \\
\hline & GO_Biological Process & regulation of natural killer cell mediated immunity & 6.68 \\
\hline & & others & 57.14 \\
\hline \multirow[t]{6}{*}{ Downregulated } & GO_Biological Process & regulation of immune system process & 15.35 \\
\hline & GO_Biological Process & inflammatory response & 11.68 \\
\hline & GO_Cellular Component & proton-transporting V-type ATPase, V1 domain & 3.00 \\
\hline & GO_Biological Process & actin cytoskeleton organization & 3.84 \\
\hline & GO_Biological Process & cell differentiation involved in kidney development & 0.25 \\
\hline & & others & 65.88 \\
\hline
\end{tabular}


transmembrane transport (e.g. ions, inorganic, and metal ions), motor activities involved in the cell cycle and sperm motility (e.g. microtubules, cilia, and the cytoskeletal motor protein dynein), and perception and response to various extracellular signals (e.g. macromolecule and growth factor stimuli). Similar to our findings, Leal and colleagues (2018) showed that enhanced nutrient supply during the pre-weaning period altered omental fat physiology of pre-weaned calves, and this was associated with an increase in omental fat mass (both hyperplasic and hypertrophic adipocyte expansion), altered biological function related to the cell cycle (e.g. mitosis and cell cycle progression), cellular assembly, organization (e.g. cytoskeleton formation) and molecular transport. Based on this evidence, it appears that PER is a target of prenatal nutrition, and PER as well as omental fat are targets of postnatal nutrition, and the long-term impacts may depend on the timing of the nutritional insult in relation to the biological window of their development [37-40].

Interestingly, early nutrition programing thus only appears to have long-term implications for some adipose tissues (perhaps depending on the timing of the intervention relative to functional development of the tissue). In PER, basic functions relating to cell structure, cytoskeletal motor function and processes involved in communicating information about the extracellular environment into the cell and cell nucleus were the targets of long-term programming, rather than metabolic processes per se. Various ion channels and transporters are involved in adipose proliferation and remodeling [41]. Metabolites such as glucose and amino acids, and ATP formation by mitochondrial activity are important facilitators for cell cycle progression [42], and these molecules are transported to the nucleus from the external environment or across mitochondrial membranes via various types of transmembrane transporters [43]. For example, ion channels have been shown to participate in the regulation of hormone release and adipocyte proliferation, of which the proliferating cells (compared to resting cells) exhibit ion channel expression. A number of ion channels have been identified in the pathogenesis of obesity [44]. Microtubule activities are crucial for the structural organization of cells, especially for maintenance of cell shape, division, motility, intracellular transport, regulation of cell polarity, modulation of cell adhesion and for control of force-production by the actin cytoskeleton $[45,46]$. In addition, microtubules are one of the essential components involved in the cell cycle, required for the segregation of the complete set of chromosomes to each daughter cell [43]. Taken together, all of these pathways were altered especially in sheep with a history of prenatal LOW nutrition, demonstrating that early nutrition programming will interfere with the ability to develop and structure a normally functioning adipose tissue and its individual cells. However, to understand the implications of this in humans will require future research.

The pathological diseases related to abdominal and/or visceral adiposity/obesity has been extensively investigated in humans and animal models [14, 47, 48]. In this respect it was interesting that a pathway related to cholesterol metabolism was enriched in the DEGs identified between LOW-HCHF and NORM-CONV sheep, and expression of the involved genes were downregulated in LOW-HCHF sheep. Obesity is known to give rise to higher levels of circulating cholesterol in the blood, and this is a recognized factor in the development of coronary heart disease and also involved in regulation of adipocyte development (reviewed in [49]). The cholesterol content of adipose tissue is positively correlated to the size of adipocytes [50, 51]. Therefore, the persistent hypercholesterolemia observed in adult LOW (but not HIGH) sheep that had been exposed to the obesogenic HCHF diet in early postnatal life [16], could be explained by an impaired cholesterol metabolism associated with a reduced adipocyte hypertrophic ability in PER of especially LOW males [15] favoring lipid overflow into the mesenteric adipose and non-adipose tissues such as liver and blood [51].

\section{Early postnatal diet induced obesity altered the mRNAs expression of PER involved in cytokine and immunity- related pathways, partly depending on the prenatal nutrition history}

Obesity is characterized by adipose tissue expansion due to increase in adipocyte size (hypertrophy) and/or numbers (hyperplasia), with visceral fat expansion as the primary target of early phase obesity development, followed by SUB, as shown using mouse models [9]. However, a sustained adipose expansion can lead to adipocyte death (apoptosis), tissue inflammation with formation of socalled crown-like structures, which ultimately results in adipose tissue dysfunction associated with various metabolic diseases [9]. Macrophages, eosinophils, $\mathrm{T}$ and $\mathrm{B}$ cells are among the immune cells responsible for the regulation of systemic as well as local immune homeostasis and inflammation, which consequently affect the adipose tissue and whole body metabolism [47, 52-54].

A maternal low-protein diet has been shown to impair development in the offspring of organs such as adipose tissues by redirecting the available nutrients to more critical organs such as the brain, and this will alter the ability of adipose tissues in postnatal life to adapt its metabolic function to a mismatching nutritional situation (e.g. a high fat diet) [48, 55-57].

In PER, we demonstrated significant alterations in the expression of mRNA playing a major role in adipose- 
related cytokine and immunity functions in both LOW and HIGH adult sheep previously exposed to the obesogenic HCHF diet, and the expression of most of the involved genes were downregulated compared to NORM-CONV sheep. These results corroborate a previous study in mice showing that maternal protein restriction during 2 weeks before mating and throughout gestation reduced the biological pathways activity related to cytokine production, innate immunity and phagocytosis in the male offspring fed a post-weaning high fatdiet. However, the authors also found increase in relative adiposity of the offspring, but this was not associated with adipose inflammation [48].

Intriguingly, the enrichment analysis of DEGs in PER, revealed that some of the DEGs were involved in biological functions related to kidney cell differentiation, and those genes were downregulated in the HCHF sheep compared to CONV sheep. In this respect, it is interesting that chronic kidney disease and compromised renal function has been associates with extreme PER expansion due to its direct functional (local toxic effects) and mechanical (compression) effects on the kidney [58-60] ascribed to their close proximity [61]. This may also contribute to the suggested regulatory role of PER on the cardiovascular system in addition to neural reflexes and adipokine secretion [62]. As previously mentioned, there was a $1 / 3$ reduction of kidney weight in lambs from this trial that had been fed the HCHF as compared to CONV diet for 6 months [17], and this can be ascribed to the extreme PER fat mass observed in these lambs. However, there was apparently a 'compensatory' growth of the kidney from adolescence until adulthood in the HCHF sheep over the following 2 years period, when they were fed a low-fat hay-based [63]. Despite an apparently normalized kidney size, renal function may, therefore, have continued to be compromised after the early obesity development, and this could contribute to explain why the adult HCHF sheep were observed to be hypercreatinaemic and hyperureaemic compared to CONV sheep [16].

Our findings suggest that extreme PER expansion during early life can have persistent and adverse implications for PER susceptibility to inflammation in adulthood, particularly in individuals with a history of late gestation malnutrition (LOW or HIGH), in addition to potentially adverse implications for redistribution of fat deposition towards the mesenteric and ectopic regions as well as adult renal function.

\section{Hub genes that were affected by early life (mal) nutrition programming}

The protein-protein interaction (PPI) network is comprised of highly connected protein nodes (known as hubs) and many poorly connected nodes. The deletion of a hub protein (gene) is thought to be more lethal than deletion of non-hub proteins [64]. This demonstrates the significance of hubs in organizing the network, which in turn suggests the biological importance of the network architecture, a key notion of systems biology [64]. Through RNA technologies (e.g. microarray and RNA-sequencing) and their respective bioinformatics downstream analyses, a vast number of hub genes (markers) related to adipose tissue and obesity comorbidities have been identified [65-67].

In PER, we identified six hub genes known as AURKA, EXO1, MELK, PDK, NDC80, and TTK, whose expressions were downregulated in sheep with a history of a LOW as compared to HIGH level of nutrition in prenatal life. In addition, CCDC39 and TKTL1 were identified as upregulated hub genes between LOW vs prenatal NORM sheep. Among these hub genes, AURKA, MELK, and TTK have previously been shown to be expressed in adipose tissues, including in specific adipose-derived mesenchymal stem cells, and they are known to participate in biological functions and pathways related to the cell cycle, ciliary disassembly, adipogenesis, immunity, cell communication, cell motility, signal transduction and others [68-72]. Mesenchymal stem cells derived from adipose tissue of obese subjects exhibited shortened and deficient cilia, triggered by upregulation of ciliary disassembly regulators, like AURKA, resulting in a defect in adipogenesis, which in turn promoted adipocyte hypertrophy during the course of obesity [70]. In contrast, in vitro studies showed that adipose-derived mesenchymal stem cells cultured at low density $(\sim 50 \%$ confluent $)$ had higher expression of proliferating-related genes, such as AURKA and TTK, whereas higher expression levels of immunity, cell communication, signal transduction and cell motility-related genes (e.g. cytokines, chemokines, and growth factors) were found in high-density cultures with $90 \%$ confluence [72]. It is possible that AURKA might play different roles depending on the state of obesity, and density of mesenchymal stem cells in adipose tissues.

In pig models, single nucleotide polymorphisms identified in the CCDC39 gene have been shown to be associated with body fatness [73], whereas reduced expression of the $P D K$ gene (involved in glucose transport regulation by insulin) were observed in insulin-resistance obese subjects. The NCD80 gene was found to be expressed in stem cells derived from human exfoliated deciduous teeth [74]. Irregular expression of NDC80 in cells is often accompanied with abnormal spindle checkpoint, abnormal chromosome separation and cell cycle disorders, and it has been found to lead to, and be highly expressed in, colon cancer cells $[74,75]$.

Based on these findings, we propose that adipocyte stem or precursor cells (involved in development and 
tissue repair) may be particular targets of long-term prenatal nutritional programming. The observations that spermatozoa, cilia and cytoskeletal motor functions were particular targets of prenatal malnutrition, suggests that fetal programming interfere with basal processes in the early assembly of (pre) adipocytes in PER. This can contribute to explain why prenatal malnutrition selectively targets certain tissues, depending on the timing of the insult relative to the specific time window of the fetal tissue formation and maturation. It can also contribute to explain why the prenatal programming is not readily apparent at birth, but only gradually becomes manifested as the individual ages and approaches adulthood.

The ITGB2 and CTSS are hub genes with reduced expression in the PER of LOW-HCHF and HIGH-HCHF sheep as compared to NORM-CONV. MMP9 was reduced in HCHF sheep compared to CONV sheep. The associations between these hub genes with obesity and obesity co-morbidities are well established. An increased expression of these hub genes were observed in SUB of obese Pima Indian subjects, and a single polymorphisms in the ITGB2 were found in Japanese Americans, whose diet has become 'Westernized' compared to native Japanese $[66,76]$. Other study showed that surgeryinduced weight loss in morbidly obese women was associated with reduced CTSS content in SUB and circulating serum [77]. In agreement with study by Taleb and colleagues [77], we found that after a 2-years long period of dietary correction on a low-fat hay based diet, the expression of CTSS (but also ITGB2) were downregulated in the LOW-HCHF and HIGH-HCHF sheep, which were obese at the end of adolescence [23] compared to NORM-CONV.

\section{Conclusions}

Our data revealed that the transcriptome of PER (but not SUB) was permanently altered by early life (mal) nutrition, with adverse implications observed particularly in adult sheep with a history of a LOW (but not HIGH) level of nutrition in late gestation upon exposure to a mismatching obesogenic diet in early postnatal life. It appears that in PER, fundamental genes (proteins) relating to biophysical sensing of the extracellular (micro) environment and early development/assembly of (pre) adipocytes are subject to fetal programming in response to late gestation LOW nutrition, which in turn might have implications for adipocytes proliferation, maturation and tissue organization. Some of the hub genes identified were AURKA, MELK, and TKT for prenatal LOW vs HIGH nutrition, and CTSS and ITGB2 for late gestation malnutrition followed by early obesity development (LOW-HCHF and HIGH-HCHF vs NORM-CONV). $M M P 9$ was the only hub genes detected to be independently affected by the early postnatal diet in PER from adult sheep. Intriguingly, the hub genes, whose expressions were altered by prenatal nutrition, have previously been shown to be expressed in adipose-derived mesenchymal stem cells and participate in biological functions crucial for adipose tissue remodeling, which could explain why programming effects become manifested only, if the programming occurs in specific windows of PER development. Affected pathways in PER furthermore included cholesterol metabolism in LOW-HCHF sheep and impaired kidney cell differentiation across all HCHF sheep, which could contribute to explain the previously reported observations of persistent hypercholesterolemia, hyperuricemia, and hypercreatinemia in the nutritionally mismatched LOW-HCHF sheep.

\section{Methods}

\section{Ethic statement}

Animal experiments were conducted at an experimental barn at Rosenlund, Lynge, Denmark under the inspection of the Faculty of Health and Medical Sciences, University of Copenhagen. All the experimental procedures were approved by the National Committee on Animal Experimentation, Denmark (License no: 2010/561-1853).

\section{Experimental design, animals, diets and tissue collection}

The experimental design (animals, diets and management) has been described elsewhere [16, 17]. In brief, the experiment was a $3 \times 2$ factorial design, in which a total of 36 twin-pregnant crossbred Texel ewes during the last 6 weeks of gestation (term $=147$ days) were allocated to three different diets: NORM (fulfilling energy and protein requirements according to Danish feeding standards), LOW (50\% of NORM) or HIGH (150 and $110 \%$ of daily energy and protein requirements, respectively). The lambs were separated from their dams 3 days after birth and twin lambs were subjected to each of their assigned diets until 6-months of age (after puberty): a moderate conventional diet, CONV (hay supplemented for the first 8 weeks of life with milk replacer; adjusted to achieve moderate and constant growth rates of approximately $225 \mathrm{~g} \mathrm{day}^{-1}$ ) or a high-carbohydrate-high-fat diet, HCHF (mix of $37 \%$ fat dairy cream with milk replacer in a $1: 1$ ratio (max. $2 \frac{1 / 2}{2} /$ day) supplemented with rolled maize (max. $2 \mathrm{~kg} /$ day) and a small amount of barley straw) (Fig. 4). Subgroups of lambs from each of the 6 treatment groups were slaughtered at 6 -months of age, while remaining animals were managed in two sexdivided groups and fed the same low-fat hay-based diet ad libitum until 2.5-years of age (supplemented with barley until 1.5-years of age). All animals had ad libitum access to water and a vitamin-mineral mix at all times. The experimental animals were slaughtered as 2.5-years old adult sheep by exsanguination, while under general anesthesia induced intravenously with Propofol (B.Braun, Melsungen, Germany; $5-6 \mathrm{mg} \mathrm{kg}^{-1}$ body weight). At 


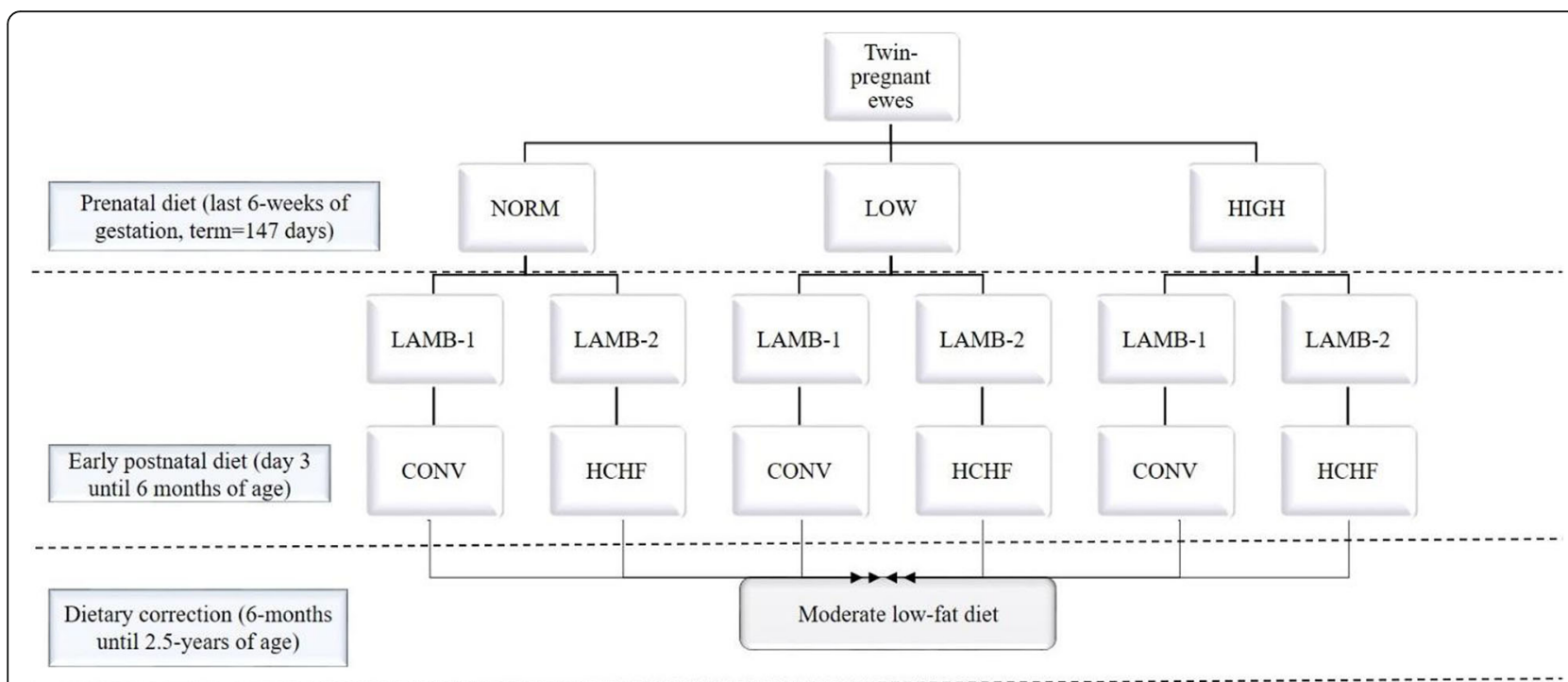

Fig. 4 The flow chart of the experimental design and treatment groups. Prenatal diet (the last 6 weeks of gestation, terms = 147 days): NORM (fulfilling 100\% of daily energy and protein requirements), LOW (providing 50\% of NORM), or HIGH (providing 150\% of daily energy and $110 \%$ of daily protein requirements). The early postnatal diet (day 3 until 6 months of age): CONV (moderate low fat diet consisting of hay supplemented during the first 8 weeks of life with milk replacer; amounts were adjusted to ensure moderate growth rates of appr. $225 \mathrm{~g} / \mathrm{d}$ ) and HCHF (highcarbohydrate (starch)-high-fat diet consisting of a mix of 37\% fat dairy cream with milk replacer in a 1:1 ratio (max. 21/2 L/d) supplemented with rolled maize (max. $2 \mathrm{~kg} / \mathrm{d}$ ) and barley straw). The experimental design thus gave rise to six treatment groups: NORM-CONV ( $N=9,5$ males:4 females), and NORM-HCHF ( $N=9,6$ males:3 females), LOW-CONV ( $N=13,6$ males:7 females), LOW-HCHF ( $N=13,5$ males:8 females), HIGH-CONV ( $N=13,5$ males:8 females), HIGH-HCHF ( $N=13,5$ males:8 females)

autopsy, specimens of subcutaneous (SUB; above the $M$. longissimus dorsi) and PER were sampled and immediately collected in RNAlater(RNAlater@Solution, Ambion, The RNA Company, USA) for $24 \mathrm{~h}$. Finally, all samples were transferred into empty tubes and stored at $-80^{\circ} \mathrm{C}$ pending analysis.

RNA isolation, CDNA library construction and sequencing Total RNA extraction, cDNA library construction and sequencing was performed by Novogene (HK) Company Limited, Hong Kong. The total RNA extraction method used was a Trizol protocol. The quality control of total RNA was performed using three methods as followed; 1) total RNA was preliminarily quantified in Nanodrop (Thermo Fisher Scientific, Carlsbad, CA, USA); 2) RNA degradation and potential contamination was tested by Agarose Gel Electrophoresis; and 3) the quantity and integrity of total RNA was checked using an Agilent 2100 Bioanalyzer (Agilent Technologies, Santa Clara, CA, USA), and RNA concentration was measured using the Qubit $^{\circ}$ RNA Assay Kit and a Qubit $^{\circ}$ 2.0 Fluorometer (Life Technologies, Carlsbad, CA, USA).

After quality control of RNA, ribosomal RNAs (rRNAs) were removed by Ribo-Zero ${ }^{\mathrm{ma}}$ rRNA Removal Kit (EPICENTRE ${ }^{\oplus}$ Biotechnologies, Madison, Wisconsin, USA). The purified RNA was first fragmented randomly to short fragments of 250 and 300 based-pair in fragmentation buffer, and then the first-strand cDNA was synthesized by adding random hexamer primers. After that, a custom second-strand synthesis buffer (Illumina, USA), dNTPs (dUTP, dATP, dGTP and dCTP) and DNA polymerase I were added to synthesize the secondstrand. The resulting double-stranded DNA was purified by AMpure XP beads, and a poly A tail was ligated to the sequencing joint. The correct-sized fragments were purified by AMPure XP beads. The USER Enzyme (USER ${ }^{\circ}$ Enzyme, New England, BioLabs ${ }^{\circ}$ Inc., UK) was used to degrade the cDNA strands containing $\mathrm{U}$ instead of $\mathrm{T}$, and the first strand cDNA was sequenced, thereby preserving the direction of the RNA. Finally, PCR amplification was conducted and the products were purified (AMPure XP beads) for constructing the cDNA libraries. The quality of the latter was assessed using Agilent BioAnalyzer 2100 system and qPCR. The libraries were sequenced on an Illumina Hiseq 4000 platform, and 150 long paired-end reads were generated.

\section{RNA-Seq and statistical analysis}

The bioinformatic pipeline for identification of differentially expressed genes (DEGs) is depicted in Fig. 5. The sequence quality or paired-end reads of each sample were assessed using FastQC v0.11.8 [78]. The result showed high quality of the raw sequences, but different levels of rRNA sequences. The Trimmomatic v0.39 [79] was used to remove potential adapter sequences and trimming of low quality reads. To achieve optimal 


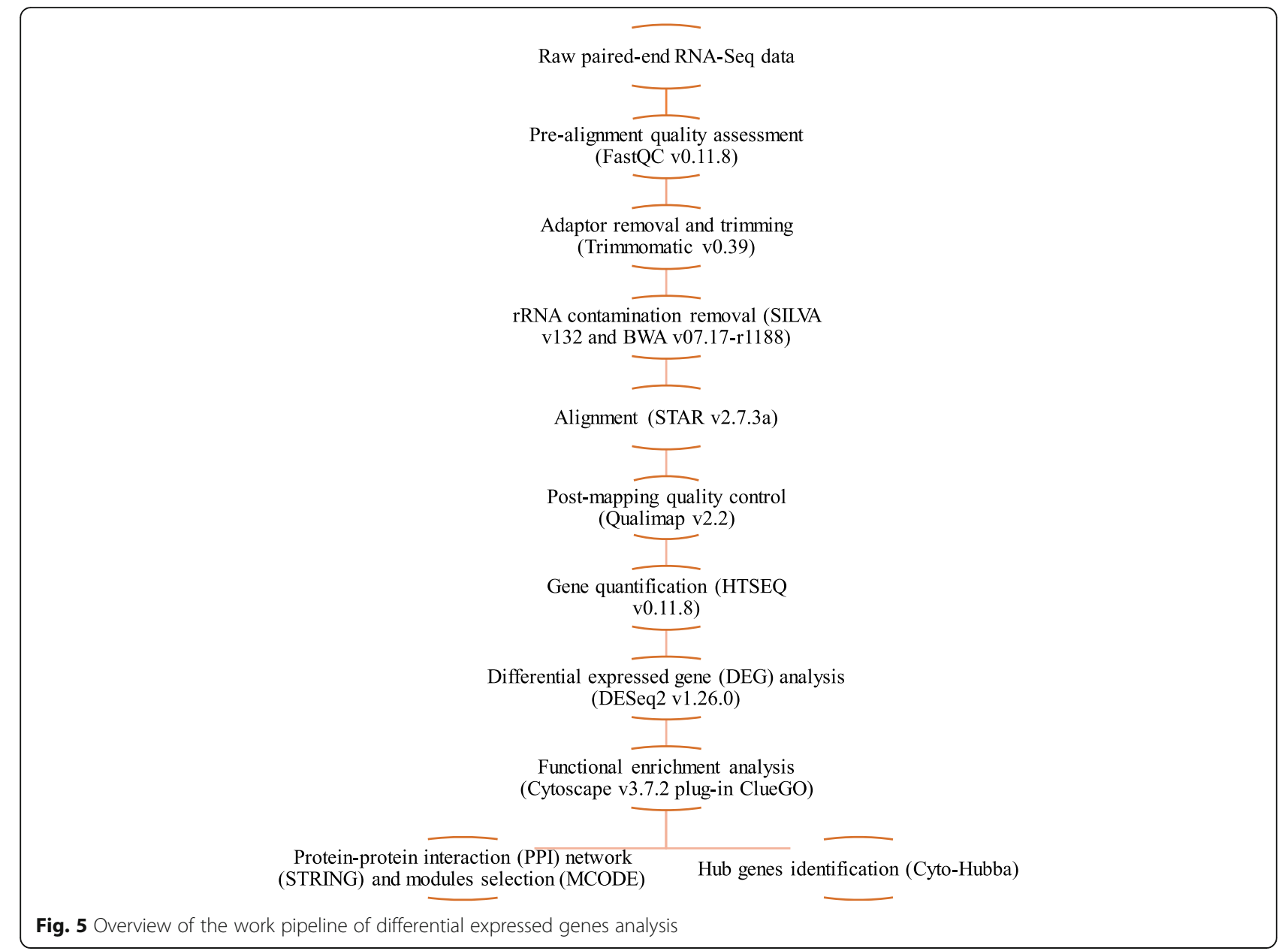

coverage, good detection sensitivity, and reliable results, screening and removal of rRNA contamination of the paired-end reads were done using the database from SILVA v132 [80]. The rRNA sequences were retried from SILVA, and the Burrows-Wheeler-Aligner (BWA) v0.7.17-r1188 software [81] was used to build the index file for BWA. The BWA-MEM was used to map to the clean data to the SILVA database, and then the pairedend unmapped sequences were extracted using samtools v1.10 [82] and bedtools v2.29.2 [83]. The generated 'clean reads' were used for all the subsequent downstream bioinformatics analyses. The paired-end clean reads of each sample were mapped to the reference genome Oar v3.1.99 gtf [84] using STAR v2.7.3a [85] with a maximum of 8 mismatches allowed, and others parameters were set as default. A post-alignment quality control was performed on the alignment files using Qualimap v2.2 [86]. After mapping, each sequence alignment map (SAM) file obtained was sorted and transformed into a binary alignment map (BAM) file by Samtools v1.9 [82], and used for the gene counting. The gene expression counts were computed using HTSeq vo.11.8 [87]. The low count genes were filtered by excluding less than 1 count per million (cpm) and the DEGs were identified using DESeq2 v1.26.0 package [88] in RStudio (v1.2.5042) [89]. The DEGs were considered at a False Discovery Rate $(\mathrm{FDR})<0.05$. The gene counts were normalized using the default normalization procedures provided by DESeq2 (correcting for the library size and RNA composition biases) and fitted with the following model:

$$
\begin{gathered}
Y=\operatorname{sex}+\text { Post } N+\text { PreN }+ \text { sex }: \text { Post } N \\
+ \text { sex }: \text { PreN }+ \text { Post } N: \text { PreN }
\end{gathered}
$$

Where $Y$ is the gene expression count, PreN is the fixed effect of prenatal nutrition (NORM, LOW and HIGH), Post $N$ is the fixed effect of the early postnatal nutrition (CONV and HCHF), and sex is the fixed effect of sex $(\hat{O}=$ males and $q=$ females $)$. In the analyses, we considered the two-way interaction terms of sex: Post $N$ $(2$ PostN $\times 2$ sex $)$, sex: PreN (3 prenatal nutrition $\times 2$ sex $)$ and PostN: PreN (3 prenatal nutrition $\times 2$ early postnatal nutrition). 
Top modules selection and hub genes identification via protein-protein interaction (PPI) network

To select the top significant modules and identify the hub genes, we followed the method described by Yang et al. [90]. First, the PPI network was constructed to evaluate the DEGs relationship with a high-confidence score $>0.7$ defined as significant using the Cytoscape StringApp [91]. Secondly, screening of sub-clusters (modules) of PPI networks was performed through the Molecular Complex Detection (MCODE) [92] application in Cytoscape. The MCODE criteria were set default with degree of cutoff $=2$, node score cutoff $=0.2$, and $\mathrm{k}$ core, maximum depth $=100$. The modules with more than 6 nodes (genes) were selected as top modules followed by the functional enrichment analysis of these modules using Cytoscape v3.7.2 plug-in ClueGO [91, 93]. The hub genes were identified using the CytoHubba application in Cytoscape through four centrality methods, including Degree, Edge Percolated Component (EPC), Eccentricity, and Maximum Neighborhood Component (MNC) [94] with the cutoff criterion of $>10$ top DEGs for further selection of hub genes [90]. The top 10 DEGs, which fell within the intersection of these four algorithm methods, were visualized in a Venn plot (http:// bioinformatics.psb.ugent.be/webtools/Venn/), and were selected as hub genes.

\section{Functional enrichment analysis}

The functional enrichment analysis was performed to further explore the biological functions and pathways associated with the significant DEGs. Each DEG set identified with padj $<0.05$ were grouped into two sets of downregulated or upregulated genes, and were imported into Cytoscape v3.7.2 plug-in ClueGO [93, 95] to find significant enrichments using Ovis aries (Taxonomy ID: 9940) as the reference organism. The selection criteria for Gene Ontology (GO) terms (Biological Process, Cellular Component and Molecular Process) and Kyoto Encyclopedia of Genes and Genomes (KEGG) pathways were based on two-sided hypergeometric tests with $P$-value threshold $<0.05$, which was corrected for multiple testing using the Benjamini-Hochberg false discovery rate (padj). Thresholds of a minimum of 3-20 GO levels, and a minimum number of 3 genes, or at least $4 \%$ genes in the respective terms, were applied.

\section{Abbreviations}

bp: Based-paired; BAM: Binary Alignment Map; CFP: Central for Foetal Programming; CDNA: Complementary DNA; CONV: Conventional low fat haybased diet; DEGs: Differential Expressed Genes; EPC: Edge Percolated Component; FC: Fold Change; GO: Gene Ontology; HCHF: High-Fat-HighCarbohydrate; PreNxsex: Interactions of prenatal nutrition and sex; KEGG: Kyoto Encyclopedia of Genes and Genome; log2FC: Log2 Fold Change; MNC: Maximum Neighborhood Component; mRNA: Messenger RNA; MCODE: Molecular Complex Detection; NORM: Normal nutrition;
HIGH: Overnutrition; PER: Perirenal adipose tissue; PCR: Polymerase Chain Reaction; PostN: Postnatal nutrition; PreN: Prenatal nutrition; PPI: ProteinProtein Interaction; qPCR: Quantitative Real-Time Polymerase Chain Reaction; RNA: Ribonucleic Acid; rRNA: Ribosomal RNA; SAM: Sequence Alignment Map; SUB: Subcutaneous adipose tissue; LOW: Undernutrition

\section{Supplementary Information}

The online version contains supplementary material available at https://doi. org/10.1186/s12864-021-07672-5.

Additional file 1: Table S1. The list of differential expressed genes for males versus females in subcutaneous adipose tissue.

Additional file 2: Figure S1 A-F. The protein-protein interaction (PPI) networks of differentially expressed genes (DEGs). A) LOW vs HIGH, B) LOW vs NORM, C) interaction effect of prenatal nutrition and sex (PreNxsex), D) LOW-HCHF vs NORM-CONV, E) HIGH-HCHF vs NORM-CONV, and F) HCHF vs CONV. The red and green nodes represent upregulated and downregulated genes, respectively. The nodes with octagon shape are the hub genes. Figure S2A-E: Functional enrichment networks. A and $\mathrm{B}$ ) module 1 and module 2 for LOW vs HIGH, C) module 2 for the interaction of prenatal nutrition and sex, D) module 1 for LOW-HCHF and HIGH-HCHF vs NORM-CONV and E) module 1 for HCHF vs CONV.

\section{Acknowledgements}

We thank our colleague, Wellison Jarles Da Silva Diniz for his valuable advice and knowledge sharing in regards to the transcriptomic analyses presented in this study.

\section{Authors' contributions}

MON was the principle investigator of this project. SA and MON interpreted the results and were major contributors in writing the manuscript. SA mainly performed the bioinformatics analyses with the help from MHD, ZC, and SMS. All authors contributed to the revision of the article. SA and MON had the primary responsibility for the content of the paper. All authors read and approved the final manuscript.

\section{Authors' information}

${ }^{1}$ Nutrition Research Unit, Department of Animal Science, Aarhus University, Blichers Alle 20, 8830 Tjele, Denmark, a PhD student (Sharmila Ahmad) and Professor of Production and lactation physiology in ruminants (Mette Olaf Nielsen), ${ }^{2}$ Novo Nordisk Foundation Center for Basic Metabolic Research, Faculty of Health and Medical Sciences, University of Copenhagen, Blegdamsvej 3B, 2200, Copenhagen, Denmark, a postdoctoral researcher, PhD, ${ }^{3}$ Department of Animal Science, Universiti Putra Malaysia, 43,400 Serdang, Selangor, Malaysia, senior lecturer, PhD, ${ }^{4}$ Department of Animal Nutrition and Management, Swedish University of Agricultural Sciences, 750 07 Uppsala, Sweden, a postdoctoral researcher, ${ }^{5}$ Centre for Quantitative Genetics and Genomics, Blichers Alle 20, 8830 Tjele, Denmark, a postdoctoral researcher, $\mathrm{PhD}$

\section{Funding}

This study was part of the research programme of the Center for Foetal Programming (CFP), Denmark, and animal experiments were funded by the Danish Council for Strategic Research (grant 09067124) and the RNAsequencing analyses were funded by the Ministry of Higher Education, Malaysia. The main authors PhD scholarship was sponsored by the Ministry of Higher Education, Malaysia and the Universiti Putra Malaysia.

\section{Availability of data and materials}

The data presented in this work is available within this paper and its Additional files 1 and 2. The RNA-Seq data analyzed, discussed and presented in this study was deposited in NCBI's Gene Expression Omnibus (GEO) and are accessible through GEO series accession number GSE166662 in the following link: https://www.ncbi.nlm.nih.gov/geo/query/acc.cgi?acc= GSE166662. 


\section{Declarations}

\section{Ethics approval and consent to participate}

All the experimental animal handling procedures were approved by the Danish National Committee on Animal Experimentation (License no: 2010/ 561-1853). All methods were carried out in accordance with the relevant guidelines and regulations. The study was carried out in compliance with the ARRIVE guidelines.

\section{Consent for publication}

Not applicable.

\section{Competing interests}

The authors declare that they have no competing interests.

\begin{abstract}
Author details
${ }^{1}$ Nutrition Research Unit, Department of Animal Science, Aarhus University, Blichers Alle 20, 8830 Tjele, Denmark. ${ }^{2}$ Novo Nordisk Foundation Center for Basic Metabolic Research, Faculty of Health and Medical Sciences, University of Copenhagen, Blegdamsvej 3B, 2200 Copenhagen, Denmark. ${ }^{3}$ Department of Animal Science, Universiti Putra Malaysia, 43400 Serdang, Selangor, Malaysia. ${ }^{4}$ Department of Animal Nutrition and Management, Swedish University of Agricultural Sciences, 75007 Uppsala, Sweden. ${ }^{5}$ Centre for Quantitative Genetics and Genomics, Aarhus University, Blichers Alle 20, 8830 Tjele, Denmark.
\end{abstract}

Received: 1 February 2021 Accepted: 30 April 2021 Published online: 11 May 2021

\section{References}

1. Mostyn A, Symonds ME. Early programming of adipose tissue function: a large-animal perspective: symposium on 'Frontiers in adipose tissue biology'. Proc Nutr Soc. 2009;68(4):393-400. https://doi.org/10.1017/S002 966510999022X

2. Sharkey D, Gardner DS, Fainberg HP, Sébert S, Bos P, Wilson V, et al. Maternal nutrient restriction during pregnancy differentially alters the unfolded protein response in adipose and renal tissue of obese juvenile offspring. FASEB J. 2009;23(5):1314-24. https://doi.org/10.1096/fj.08-114330.

3. Moreno-Mendez E, Quintero-Fabian S, Fernandez-Mejia C, Lazo-de-la-VegaMonroy ML. Early-life programming of adipose tissue. Nutr Res Rev. 2020;33: 244-59.

4. Grundy SM. Adipose tissue and metabolic syndrome: too much, too little or neither. Eur J Clin Investig. 2015;45(11):1209-17. https://doi.org/10.1111/ eci.12519.

5. Stenkula KG, Erlanson-Albertsson C. Adipose cell size: importance in health and disease. Am J Phys Regul Integr Comp Phys. 2018;315(2):R284-R95. https://doi.org/10.1152/ajpregu.00257.2017.

6. Tan CY, Vidal-Puig A. Adipose tissue expandability: the metabolic problems of obesity may arise from the inability to become more obese: Portland Press Limited; 2008.

7. Manolopoulos K, Karpe F, Frayn K. Gluteofemoral body fat as a determinant of metabolic health. Int J Obes. 2010;34(6):949-59. https://doi.org/10.1038/ ijo.2009.286

8. Moreno-Indias I, Tinahones FJ. Impaired adipose tissue expandability and lipogenic capacities as ones of the main causes of metabolic disorders. J Diab Res. 2015;2015:1-12. https://doi.org/10.1155/2015/970375.

9. Pellegrinelli V, Carobbio S, Vidal-Puig A. Adipose tissue plasticity: how fat depots respond differently to pathophysiological cues. Diabetologia. 2016; 59(6):1075-88. https://doi.org/10.1007/s00125-016-3933-4.

10. Björntorp P. Body fat distribution, insulin resistance, and metabolic diseases. Nutrition. 1997;13(9):795-803. https://doi.org/10.1016/S0899-9007(97)00191-3.

11. Samara A, Ventura E, Alfadda A, Goran M. Use of MRI and CT for fat imaging in children and youth: what have we learned about obesity, fat distribution and metabolic disease risk? Obes Rev. 2012;13(8):723-32. https://doi.org/1 0.1111/j.1467-789X.2012.00994.x.

12. Shuster A, Patlas M, Pinthus J, Mourtzakis M. The clinical importance of visceral adiposity: a critical review of methods for visceral adipose tissue analysis. Br J Radiol. 2012;85(1009):1.

13. Fang L, Guo F, Zhou L, Stahl R, Grams J. The cell size and distribution of adipocytes from subcutaneous and visceral fat is associated with type 2 diabetes mellitus in humans. Adipocyte. 2015;4(4):273-9. https://doi.org/10.1 080/21623945.2015.1034920.

14. Foster MC, Hwang S-J, Porter SA, Massaro JM, Hoffmann U, Fox CS. Fatty kidney, hypertension, and chronic kidney disease: the Framingham heart study. Hypertension. 2011;58(5):784-90. https://doi.org/10.1161/ HYPERTENSIONAHA.111.175315.

15. Ahmad S, Lyngman LK, Mansouryar M, Dhakal R, Agerholm JS, Khanal P, et al. Depot and sex-specific implications for adipose tissue expandability and functional traits in adulthood of late prenatal and early postnatal malnutrition in a precocial sheep model. Physiol Rep. 2020;8(19):e14600.

16. Khanal P, Johnsen L, Axel AMD, Hansen PW, Kongsted AH, Lyckegaard NB, et al. Long-term impacts of foetal malnutrition followed by early postnatal obesity on fat distribution pattern and metabolic adaptability in adult sheep. PLoS One. 2016;11(6):e0156700.

17. Khanal P, Husted SV, Axel A-MD, Johnsen L, Pedersen KL, Mortensen MS, et al. Late gestation over-and undernutrition predispose for visceral adiposity in response to a post-natal obesogenic diet, but with differential impacts on glucose-insulin adaptations during fasting in lambs. Acta Physiol. 2014:210(1):110-26. https://doi.org/10.1111/apha.12129.

18. Clément K, Langin D. Regulation of inflammation-related genes in human adipose tissue. J Intern Med. 2007;262(4):422-30. https://doi.org/10.1111/j.13 65-2796.2007.01851.x.

19. Duffield JA, Vuocolo T, Tellam R, McFarlane JR, Kauter KG, Muhlhausler BS, et al. Intrauterine growth restriction and the sex specific programming of leptin and peroxisome proliferator-activated receptor $\gamma$ (PPAR $\gamma$ ) mRNA expression in visceral fat in the lamb. Pediatr Res. 2009;66(1):59-65. https:// doi.org/10.1203/PDR.0b013e3181a7c121.

20. Faulconnier $Y$, Chilliard $Y$, Torbati MM, Leroux $C$. The transcriptomic profiles of adipose tissues are modified by feed deprivation in lactating goats. Comp Biochem Physiol Part D Genomics Proteomics. 2011;6(2):139-49.

21. Peñagaricano $F$, Wang $X$, Rosa GJ, Radunz AE, Khatib H. Maternal nutrition induces gene expression changes in fetal muscle and adipose tissues in sheep. BMC Genomics. 2014;15(1):1034. https://doi.org/10.1186/1471-2164-1 5-1034.

22. Grant RW, Vester Boler BM, Ridge TK, Graves TK, Swanson KS. Adipose tissue transcriptome changes during obesity development in female dogs. Physiol Genomics. 2011;43(6):295-307. https://doi.org/10.1152/physiolgenomics.001 90.2010.

23. Khanal P, Pandey D, Binti Ahmad S, Safayi S, Kadarmideen HN, Olaf NM. Differential impacts of late gestational over-and undernutrition on adipose tissue traits and associated visceral obesity risk upon exposure to a postnatal high-fat diet in adolescent sheep. Physiol Rep. 2020;8(3):e14359. https://doi.org/10.14814/phy2.14359.

24. Fuente-Martín E, Argente-Arizón P, Ros P, Argente J, Chowen JA. Sex differences in adipose tissue: it is not only a question of quantity and distribution. Adipocyte. 2013;2(3):128-34. https://doi.org/10.4161/adip.24075.

25. Bloor ID, Sébert SP, Saroha V, Gardner DS, Keisler DH, Budge H, et al. Sex differences in metabolic and adipose tissue responses to juvenile-onset obesity in sheep. Endocrinology. 2013;154(10):3622-31. https://doi.org/10.1210/en.2013-1207.

26. Khanal P, AM DA, Safayi S, Elbrønd VS, Nielsen MO. Prenatal over-and undernutrition differentially program small intestinal growth, angiogenesis, absorptive capacity, and endocrine function in sheep. Physiol Rep. 2020; 8(12):e14498.

27. Karastergiou K, Smith SR, Greenberg AS, Fried SK. Sex differences in human adipose tissues-the biology of pear shape. Biol Sex Differ. 2012;3(1):13. https://doi.org/10.1186/2042-6410-3-13

28. Medrikova D, Jilkova Z, Bardova K, Janovska P, Rossmeisl M, Kopecky J. Sex differences during the course of diet-induced obesity in mice: adipose tissue expandability and glycemic control. Int J Obes. 2012;36(2):262-72 https://doi.org/10.1038/ijo.2011.87.

29. Gealekman O, Guseva N, Hartigan C, Apotheker S, Gorgoglione M, Gurav K, et al. Depot-specific differences and insufficient subcutaneous adipose tissue angiogenesis in human obesity. Circulation. 2011;123(2):186-94. https://doi.org/10.1161/CIRCULATIONAHA.110.970145.

30. Porter SA, Massaro JM, Hoffmann U, Vasan RS, O'Donnel CJ, Fox CS. Abdominal subcutaneous adipose tissue: a protective fat depot? Diabetes Care. 2009;32(6):1068-75. https://doi.org/10.2337/dc08-2280.

31. Tchkonia T, Thomou T, Zhu Y, Karagiannides I, Pothoulakis C, Jensen MD, et al. Mechanisms and metabolic implications of regional differences among fat depots. Cell Metab. 2013;17(5):644-56. https://doi.org/10.1016/j. cmet.2013.03.008 
32. O'Connell J, Lynch L, Cawood TJ, Kwasnik A, Nolan N, Geoghegan J, et al. The relationship of omental and subcutaneous adipocyte size to metabolic disease in severe obesity. PloS One. 2010;5(4):e9997.

33. Cuthbertson DJ, Steele T, Wilding JP, Halford J, Harrold JA, Hamer M, et al. What have human experimental overfeeding studies taught us about adipose tissue expansion and susceptibility to obesity and metabolic complications? Int J Obes. 2017;41(6):853-65. https://doi.org/1 0.1038/ijo.2017.4.

34. Sniderman AD, Bhopal R, Prabhakaran D, Sarrafzadegan N, Tchernof A. Why might south Asians be so susceptible to central obesity and its atherogenic consequences? The adipose tissue overflow hypothesis. Int J Epidemiol. 2007;36(1):220-5. https://doi.org/10.1093/ije/dyl245.

35. Sarr O, Gondret F, Jamin A, Le Huërou-Luron I, Louveau I. A high-protein neonatal formula induces a temporary reduction of adiposity and changes later adipocyte physiology. Am J Phys Regul Integr Comp Phys. 2011;300(2): R387-R97. https://doi.org/10.1152/ajpregu.00459.2010.

36. Gondret F, Vincent A, Houée-Bigot M, Siegel A, Lagarrigue S, Louveau I, et al. Molecular alterations induced by a high-fat high-fiber diet in porcine adipose tissues: variations according to the anatomical fat location. BMC Genomics. 2016;17(1):120. https://doi.org/10.1186/s12864-016-2438-3.

37. Gemmell R, Alexander G. Ultrastructural development of adipose tissue in foetal sheep. Aust J Biol Sci. 1978;31(5):505-16. https://doi.org/10.1071/ B19780505.

38. Symonds ME, Pearce S, Bispham J, Gardner DS, Stephenson T. Timing of nutrient restriction and programming of fetal adipose tissue development Proc Nutr Soc. 2004;63(3):397-403. https://doi.org/10.1079/PNS2004366.

39. Symonds ME, Mostyn A, Pearce S, Budge H, Stephenson T. Endocrine and nutritional regulation of fetal adipose tissue development. J Endocrinol. 2003;179(3):293-9. https://doi.org/10.1677/joe.0.1790293.

40. Bonnet M, Cassar-Malek I, Chilliard Y, Picard B. Ontogenesis of muscle and adipose tissues and their interactions in ruminants and other species. Animal. 2010;4(7):1093-109. https://doi.org/10.1017/S1751731110000601.

41. Zheng M, Kim D-Y, Sung J-H. lon channels and transporters in adiposederived stem cells. J f Pharm Invest. 2019;49(3):287-94. https://doi.org/10.1 007/s40005-018-00413-z.

42. Björklund M. Cell size homeostasis: metabolic control of growth and cell division. Biochimica et Biophysica Acta (BBA)-molecular. Cell Res. 2019; 1866(3):409-17.

43. Gadde $S$, Heald R. Mechanisms and molecules of the mitotic spindle. Curr Biol. 2004;14(18):R797-805. https://doi.org/10.1016/j.cub.2004.09.021.

44. Vasconcelos LH, Souza IL, Pinheiro LS, Silva BA. Ion channels in obesity: pathophysiology and potential therapeutic targets. Front Pharmacol. 2016;7:58.

45. Kaverina I, Straube A. Regulation of cell migration by dynamic microtubules. Seminars in Cell \& Developmental Biology: Elsevier; 2011.

46. Matis $M$. The mechanical role of microtubules in tissue remodeling. BioEssays. 2020;42(5):1900244. https://doi.org/10.1002/bies.201900244.

47. Gerriets VA, Maclver NJ. Role of T cells in malnutrition and obesity. Front Immunol. 2014;5:379.

48. Kim J, Choi A, Kwon YH. Maternal protein restriction altered insulin resistance and inflammation-associated gene expression in adipose tissue of young adult mouse offspring in response to a high-fat diet. Nutrients. 2020; 12(4):1103. https://doi.org/10.3390/nu12041103.

49. Aguilar D, Fernandez ML. Hypercholesterolemia induces adipose dysfunction in conditions of obesity and nonobesity. Adv Nutr. 2014;5(5): 497-502. https://doi.org/10.3945/an.114.005934.

50. Krause BR, Hartman AD. Adipose tissue and cholesterol metabolism. J Lipid Res. 1984;25(2):97-110. https://doi.org/10.1016/S0022-2275(20)37830-5.

51. Zhang T, Chen J, Tang X, Luo Q, Xu D, Yu B. Interaction between adipocytes and high-density lipoprotein: new insights into the mechanism of obesityinduced dyslipidemia and atherosclerosis. Lipids Health Dis. 2019;18(1):223. https://doi.org/10.1186/s12944-019-1170-9

52. Huh JY, Park YJ, Ham M, Kim JB. Crosstalk between adipocytes and immune cells in adipose tissue inflammation and metabolic dysregulation in obesity. Mol Cells. 2014;37(5):365-71. https://doi.org/10.14348/molcells.2014.0074.

53. Lu J, Zhao J, Meng H, Zhang X. Adipose tissue-resident immune cells in obesity and type 2 diabetes. Front Immunol. 2019;10:1173. https://doi.org/1 0.3389/fimmu.2019.01173.

54. Wang Q, Wu H. T cells in adipose tissue: critical players in Immunometabolism. Front Immunol. 2018:9:2509. https://doi.org/10.3389/ fimmu.2018.02509.
55. Ozanne SE, Hales CN. The long-term consequences of intra-uterine protein malnutrition for glucose metabolism. Proc Nutr Soc. 1999;58(3):615-9. https://doi.org/10.1017/S0029665199000804.

56. Ozanne S, Smith G, Tikerpae J, Hales C. Altered regulation of hepatic glucose output in the male offspring of protein-malnourished rat dams. Am J Physiol Endocrinol Metab. 1996;270(4):E559-E64. https://doi.org/10.1152/a jpendo.1996.270.4.E559.

57. Souza-Mello V, Mandarim-de-Lacerda CA, Aguila MB. Hepatic structural alteration in adult programmed offspring (severe maternal protein restriction) is aggravated by post-weaning high-fat diet. Br J Nutr. 2007 . 98(6):1159-69. https://doi.org/10.1017/S0007114507771878.

58. Cordeiro AC, Qureshi AR, Lindholm B, Amparo FC, Tito-Paladino-Filho A, Perini $M$, et al. Visceral fat and coronary artery calcification in patients with chronic kidney disease. Nephrol Dial Transplant. 2013;28(suppl_4):iv152-iv9.

59. Declèves A-E, Sharma K. Obesity and kidney disease: differential effects of obesity on adipose tissue and kidney inflammation and fibrosis. Curr Opin Nephrol Hypertens. 2015;24(1):28-36. https://doi.org/10.1097/MNH. 0000000000000087.

60. Yun $\mathrm{C}-\mathrm{H}$, Lin T-Y, Wu Y-J, Liu C-C, Kuo J-Y, Yeh H-I, et al. Pericardial and thoracic peri-aortic adipose tissues contribute to systemic inflammation and calcified coronary atherosclerosis independent of body fat composition, anthropometric measures and traditional cardiovascular risks. Eur J Radiol. 2012;81(4):749-56. https://doi.org/10.1016/j.ejrad.2011.01.035.

61. Hall JE, do Carmo JM, da Silva AA, Wang Z, Hall ME. Obesity-induced hypertension: interaction of neurohumoral and renal mechanisms. Circ Res. 2015;116(6):991-1006. https://doi.org/10.1161/CIRCRESAHA.116.305697.

62. Liu B-X, Sun W, Kong X-Q. Perirenal fat: a unique fat pad and potential target for cardiovascular disease. Angiology. 2019;70(7):584-93. https://doi. org/10.1177/0003319718799967.

63. Khanal P, Axel AMD, Kongsted AH, Husted SV, Johnsen L, Pandey D, et al. Late gestation under-and overnutrition have differential impacts when combined with a post-natal obesogenic diet on glucose-lactate-insulin adaptations during metabolic challenges in adolescent sheep. Acta Physiol. 2015;213(2):519-36. https://doi.org/10.1111/apha.12391.

64. He X, Zhang J. Why do hubs tend to be essential in protein networks? PLoS Genet. 2006;2(6):e88. https://doi.org/10.1371/journal.pgen.0020088.

65. Kogelman LJ, Cirera S, Zhernakova DV, Fredholm M, Franke L, Kadarmideen HN. Identification of co-expression gene networks, regulatory genes and pathways for obesity based on adipose tissue RNA sequencing in a porcine model. BMC Med Genet. 2014;7(1):57. https://doi.org/10.1186/1755-8794-7-57.

66. Awaya T, Yokosaki Y, Yamane K, Usui H, Kohno N, Eboshida A. Geneenvironment association of an ITGB2 sequence variant with obesity in ethnic Japanese. Obesity. 2008;16(6):1463-6. https://doi.org/10.1038/ oby.2008.68.

67. Xu X, Grijalva A, Skowronski A, van Eijk M, Serlie MJ, Ferrante AW Jr. Obesity activates a program of lysosomal-dependent lipid metabolism in adipose tissue macrophages independently of classic activation. Cell Metab. 2013; 18(6):816-30. https://doi.org/10.1016/j.cmet.2013.11.001.

68. Cook NT. Bioinformatic analysis of adipose tissue Transcriptome of broiler chickens: Tennessee State University; 2016.

69. Ritter A, Louwen F, Yuan J. Deficient primary cilia in obese adipose-derived mesenchymal stem cells: obesity, a secondary ciliopathy? Obes Rev. 2018; 19(10):1317-28. https://doi.org/10.1111/obr.12716.

70. Ritter A, Friemel A, Kreis N-N, Hoock SC, Roth S, Kielland-Kaisen U, et al. Primary cilia are dysfunctional in obese adipose-derived mesenchymal stem cells. Stem Cell Rep. 2018;10(2):583-99. https://doi.org/10.1016/j.stemcr.201 7.12 .022 .

71. Xu Z-P, Wawrousek EF, Piatigorsky J. Transketolase haploinsufficiency reduces adipose tissue and female fertility in mice. Mol Cell Biol. 2002 22(17):6142-7. https://doi.org/10.1128/MCB.22.17.6142-6147.2002.

72. Kim DS, Lee MW, Yoo KH, Lee T-H, Kim HJ, Jang IK, et al. Gene expression profiles of human adipose tissue-derived mesenchymal stem cells are modified by cell culture density. PLoS One. 2014;9(1):e83363. https://doi. org/10.1371/journal.pone.0083363.

73. Fowler KE, Pong-Wong R, Bauer J, Clemente EJ, Reitter CP, Affara NA, et al. Genome wide analysis reveals single nucleotide polymorphisms associated with fatness and putative novel copy number variants in three pig breeds. BMC Genomics. 2013;14(1):784. https://doi.org/10.1186/1471-2164-14-784.

74. Peng $W X$, Gao $C H$, Huang GB. High throughput analysis to identify key gene molecules that inhibit adipogenic differentiation and promote 
osteogenic differentiation of human mesenchymal stem cells. Exp Ther Med. 2019;17(4):3021-8. https://doi.org/10.3892/etm.2019.7287.

75. Xing XK, Wu HY, Chen HL, Feng HG. NDC80 promotes proliferation and metastasis of colon cancer cells. Genet Mol Res. 2016;15(2).

76. Nair S, Lee Y, Rousseau E, Cam M, Tataranni P, Baier L, et al. Increased expression of inflammation-related genes in cultured preadipocytes/stromal vascular cells from obese compared with non-obese Pima Indians. Diabetologia. 2005;48(9):1784-8. https://doi.org/10.1007/s00125-005-1868-2.

77. Taleb S, Cancello R, Poitou C, Rouault C, Sellam P, Levy P, et al. Weight loss reduces adipose tissue cathepsin $\mathrm{S}$ and its circulating levels in morbidly obese women. J Clin Endocrinol Metab. 2006;91(3):1042-7. https://doi.org/1 0.1210/jc.2005-1601.

78. Andrews S. FastQC: a quality control tool for high throughput sequence data. Babraham Institute, Cambridge, United Kingdom: Babraham Bioinformatics: 2010

79. Bolger AM, Lohse M, Usadel B. Trimmomatic: a flexible trimmer for Illumina sequence data. Bioinformatics. 2014;30(15):2114-20. https://doi.org/10.1093/ bioinformatics/btu170.

80. Quast C, Pruesse E, Yilmaz P, Gerken J, Schweer T, Yarza P, et al. The SILVA ribosomal RNA gene database project: improved data processing and webbased tools. Nucleic Acids Res. 2012;41(D1):D590-D6. https://doi.org/10.1 093/nar/gks 1219.

81. Li H. Aligning sequence reads, clone sequences and assembly contigs with BWA-MEM. arXiv preprint arXiv:13033997; 2013

82. Li H, Handsaker B, Wysoker A, Fennell T, Ruan J, Homer N, et al. The sequence alignment/map format and SAMtools. Bioinformatics. 2009;25(16): 2078-9. https://doi.org/10.1093/bioinformatics/btp352.

83. Quinlan AR, Hall IM. BEDTools: a flexible suite of utilities for comparing genomic features. Bioinformatics. 2010;26(6):841-2. https://doi.org/10.1093/ bioinformatics/btq033.

84. Flicek P, Ahmed I, Amode MR, Barrell D, Beal K, Brent S, et al. Ensembl 2013. Nucleic Acids Res. 2012;41(D1):D48-55. https://doi.org/10.1093/nar/gks1236.

85. Dobin A, Davis CA, Schlesinger F, Drenkow J, Zaleski C, Jha S, et al. STAR: ultrafast universal RNA-seq aligner. Bioinformatics. 2013;29(1):15-21. https:// doi.org/10.1093/bioinformatics/bts635.

86. García-Alcalde F, Okonechnikov K, Carbonell J, Cruz LM, Götz S, Tarazona S, et al. Qualimap: evaluating next-generation sequencing alignment data. Bioinformatics. 2012;28(20):2678-9. https://doi.org/10.1 093/bioinformatics/bts503.

87. Anders S, Pyl PT, Huber W. HTSeq —a Python framework to work with highthroughput sequencing data. Bioinformatics. 2015;31(2):166-9. https://doi. org/10.1093/bioinformatics/btu638.

88. Love Ml, Huber W, Anders S. Moderated estimation of fold change and dispersion for RNA-seq data with DESeq2. Genome Biol. 2014;15(12):550 https://doi.org/10.1186/s13059-014-0550-8

89. Team R. RStudio: Integrated Development for R (1.2. 5042) [Computer software]. RStudio. Inc; 2020.

90. Yang L, He T, Xiong F, Chen X, Fan X, Jin S, et al. Identification of key genes and pathways associated with feed efficiency of native chickens based on transcriptome data via bioinformatics analysis. BMC Genomics. 2020;21:1-18.

91. Doncheva NT, Morris JH, Gorodkin J, Jensen LJ. Cytoscape StringApp: network analysis and visualization of proteomics data. J Proteome Res. 2018; 18(2):623-32. https://doi.org/10.1021/acs.jproteome.8b00702.

92. Bader $\mathrm{GD}$, Hogue $\mathrm{CW}$. An automated method for finding molecular complexes in large protein interaction networks. BMC Bioinformatics. 2003; 4(1):2. https://doi.org/10.1186/1471-2105-4-2.

93. Bindea G, Mlecnik B, Hackl H, Charoentong P, Tosolini M, Kirilovsky A, et al. ClueGO: a Cytoscape plug-in to decipher functionally grouped gene ontology and pathway annotation networks. Bioinformatics. 2009;25(8): 1091-3. https://doi.org/10.1093/bioinformatics/btp101.

94. Chin C-H, Chen S-H, Wu H-H, Ho C-W, Ko M-T, Lin C-Y. cytoHubba: identifying hub objects and sub-networks from complex interactome. BMC Syst Biol. 2014;8(S4):S11.

95. Shannon P, Markiel A, Ozier O, Baliga NS, Wang JT, Ramage D, et al. Cytoscape: a software environment for integrated models of biomolecular interaction networks. Genome Res. 2003;13(11):2498-504. https://doi.org/1 $0.1101 /$ gr. 1239303

\section{Publisher's Note}

Springer Nature remains neutral with regard to jurisdictional claims in published maps and institutional affiliations.

Ready to submit your research? Choose BMC and benefit from:

- fast, convenient online submission

- thorough peer review by experienced researchers in your field

- rapid publication on acceptance

- support for research data, including large and complex data types

- gold Open Access which fosters wider collaboration and increased citations

- maximum visibility for your research: over $100 \mathrm{M}$ website views per year

At BMC, research is always in progress.

Learn more biomedcentral.com/submissions 